\title{
Polyphenols of the Mediterranean Diet and Their Metabolites in the Prevention of Colorectal Cancer
}

\author{
Aline Yammine ${ }^{1,+}$, Amira Namsi ${ }^{1,+} \mathbb{D}$, Dominique Vervandier-Fasseur ${ }^{2} \mathbb{D}$, John J. Mackrill ${ }^{3} \mathbb{D}$, Gérard Lizard $^{1, \pm(\mathbb{D}}$ \\ and Norbert Latruffe $1, *$ (D)
}

1 Team Bio-PeroxIL, "Biochemistry of the Peroxisome, Inflammation and Lipid Metabolism" (EA7270), University of Bourgogne Franche-Comté, Inserm, 21000 Dijon, France; alineyammine5@gmail.com (A.Y.); amira.namsi@gmail.com (A.N.); gerard.lizard@u-bourgogne.fr (G.L.)

2 Team OCS, Institute of Molecular Chemistry of University of Burgundy (ICMUB UMR CNRS 6302), University of Bourgogne Franche-Comté, 21000 Dijon, France; dominique.vervandier-fasseur@u-bourgogne.fr

3 Department of Physiology, University College Cork, BioScience Institute, College Road, T12 YT20 Cork, Ireland; J.Mackrill@ucc.ie

* Correspondence: norbert.latruffe@u-bourgogne.fr; Tel.:+33-380-396-237; Fax: +33-380-396-250

+ These authors contributed equally to this work.

$\ddagger$ Inserm Researcher; Researcher attached to the international network of the UNESCO Chair 'Culture and tradition of wine'.

Citation: Yammine, A.; Namsi, A.; Vervandier-Fasseur, D.; Mackrill, J.J.; Lizard, G.; Latruffe, N. Polyphenols of the Mediterranean Diet and Their Metabolites in the Prevention of Colorectal Cancer. Molecules 2021, 26, 3483. https://doi.org/10.3390/ molecules26123483

Academic Editor: Bruno Botta

Received: 20 April 2021

Accepted: 4 June 2021

Published: 8 June 2021

Publisher's Note: MDPI stays neutral with regard to jurisdictional claims in published maps and institutional affiliations.

Copyright: (c) 2021 by the authors. Licensee MDPI, Basel, Switzerland. This article is an open access article distributed under the terms and conditions of the Creative Commons Attribution (CC BY) license (https:// creativecommons.org/licenses/by/ $4.0 /)$.
Abstract: The Mediterranean diet is a central element of a healthy lifestyle, where polyphenols play a key role due to their anti-oxidant properties, and for some of them, as nutripharmacological compounds capable of preventing a number of diseases, including cancer. Due to the high prevalence of intestinal cancer (ranking second in causing morbidity and mortality), this review is focused on the beneficial effects of selected dietary phytophenols, largely present in Mediterranean cooking: apigenin, curcumin, epigallocatechin gallate, quercetin-rutine, and resveratrol. The role of the Mediterranean diet in the prevention of colorectal cancer and future perspectives are discussed in terms of food polyphenol content, the effectiveness, the plasma level, and the importance of other factors, such as the polyphenol metabolites and the influence of the microbiome. Perspectives are discussed in terms of microbiome-dependency of the brain-second brain axis. The emergence of polyphenol formulations may strengthen the efficiency of the Mediterranean diet in the prevention of cancer.

Keywords: intestinal cancer; dietary polyphenols; Mediterranean diet; resveratrol; curcumin; quercetin; rutin; apigenin; EGCG; microbiota; polyphenol nanoformulation

\section{Introduction}

The Mediterranean diet is associated with the Mediterranean climate, which is temperate and characterized by hot and dry summers, and mild and humid winters. However, interestingly, the Mediterranean climate and diet are not restricted to Mediterranean Sea area but are also found in similar regions of the world located between 30 and $40^{\circ}$ of latitude. For instance, the western coasts of continents like America (California, mid-Chili), the Cape region in South Africa, and Australia (south and west). In all of these countries, food and beverages are quite comparable and provide good health to the populations as illustrated by the exceptional longevity of people living on Sardinia and Crete, and those of the Okinawa population. The Mediterranean diet has beneficial effects on health thanks to foods rich in polyphenols; the most abundant phytochemicals in the plant kingdom present in fruit, vegetables, wine, and honey (Table 1) [1].

The Mediterranean diet has age-cultural and nutritional aspects that contribute to wellbeing. In 2010, the UNESCO world organization added the Mediterranean diet to the list of intangible cultural heritage, where cooking is associated with the consumption of beverages (wine and/or infusions/tea) with respect to the beliefs and traditions of 
each community. Mediterranean cooking is becoming more and more popular, providing food microcomponents including polyphenols, vitamins, fiber, vegetables, olive oil, fishes rich in polyunsaturated fatty ( $\omega 3)$, and oligo-elements supplied by fruits and beverages. Besides fruits and vegetables, red wine provides additional unique polyphenols with strong anti-oxidant properties. These include resveratrol, procyanidins, and monophenols, including hydroxytyrosol and tyrosol. The Mediterranean diet is represented by a food pyramid proposed by Willett W.C. et al. [3] based on food groups, consumed weekly or less frequently.

Table 1. Total polyphenols content of main edible plants from Mediterranean diet. Adapted from Debbabi et al. [2].

\begin{tabular}{|c|c|c|c|}
\hline Fruits & $\begin{array}{c}\text { Mean of Total Polyphenol Content } \\
\text { (mg of GAE/100g Fresh } \\
\text { Edible Portion) }\end{array}$ & Vegetables & $\begin{array}{c}\text { Mean of Total Polyphenol Content } \\
\text { (mg of GAE/100 g Fresh } \\
\text { Edible Portion) }\end{array}$ \\
\hline Strawberry & 263.8 & Artichoke heart & 321.3 \\
\hline Lychee & 222.3 & Parsley & 280.2 \\
\hline Grape & 195.5 & Brussels sprout & 257.1 \\
\hline Apricot & 179.8 & Shallot & 104.1 \\
\hline Apple & 1179.1 & Broccoli & 98.9 \\
\hline Date & 99.3 & Celery & 84.7 \\
\hline Cherry & 94.3 & Onion & 79.1 \\
\hline Fig & 92.5 & Eggplant & 65.6 \\
\hline Pear & 69.2 & Garlic & 59.4 \\
\hline White nectarine & 72.7 & Turnip & 54.7 \\
\hline Passion fruit & 71.8 & Celeriac & 39.8 \\
\hline Mango & 68.1 & Radish & 38.4 \\
\hline Yellow/white peach & $59.3-44.2$ & Pea & 36.7 \\
\hline Banana & 51.5 & Leek & 32.7 \\
\hline Pineapple & 47.2 & Red bell pepper & 26.8 \\
\hline Lemon & 45 & Cherry tomato & 26.6 \\
\hline Grape fruit & 43.5 & Potato & 23.1 \\
\hline Orange & 31 & Zucchini & 18.8 \\
\hline Clementine & 30.6 & Green bell pepper & 18.2 \\
\hline Lime & 30.6 & Chicory & 14.7 \\
\hline Kiwi & 28.1 & Asparagus & 14.5 \\
\hline Watermelon & 11.6 & Tomato & 13.7 \\
\hline \multirow[t]{5}{*}{ melon } & 7.8 & Fennel & 13 \\
\hline & & Cauliflower & 12.5 \\
\hline & & Carrot & 10.1 \\
\hline & & French string bean & 10 \\
\hline & & Avocado & 3.6 \\
\hline
\end{tabular}

There are about 8000 different dietary polyphenols, divided into two major classes: (i) Flavonoids which include other subclasses based on their chemical structure such as (flavanols, isoflavones, flavanones, flavonones, and anthocyanidins) and (ii) non-flavonoids divided into different groups (phenolic acids, stilbenes, and lignans; tannins are flavonoid polymers) [4]. The Table 2 illustrates the polyphenol profiles of some fruits and vegetables of the Mediterranean diet that have important anti-oxidant potential and a high polyphenol content [2]. 
Table 2. Fruit and vegetables with high polyphenols content characterized by important anti-oxidant activity. Adapted from Debbabi et al. [2].

\begin{tabular}{|c|c|}
\hline Extracts & Polyphenols Expressed in (mg/100 g of Fresh Matter) \\
\hline Muscat grape & $\begin{array}{c}\text { Gallic acid (1.7), epigallocatechin (10.8), catechin (21.8), epicatechin } \\
\text { (5.3), quercetin-3-O-beta-D-glucuronide (10.8) }\end{array}$ \\
\hline White grape & $\begin{array}{l}\text { Gallic acid (1.1), caftaric acid (10.8), epigallocatechin (4.4), catechin } \\
(10.6) \text {, epicatechin (6.0), quercetin-3-O-beta-D-glucuronide (1.7) }\end{array}$ \\
\hline Strawberry & $\begin{array}{c}\text { Epigallocatechin (6.3), catechin (7.1), epicatechin (4.1), epicatechin } \\
\text { gallate (1.3), quercetin-3-O-beta-D-glucuronide (15.4), } \\
\text { kaempferol-3-O-glucoside (2.6) }\end{array}$ \\
\hline Raspberry & Rutin (1.6), quercetin-3-O-beta-D-glucuronide (1.7) \\
\hline Beans & $\begin{array}{c}\text { Catechin (1.0), myricetin-3-O-glucoside (12.0), rutin (0.8), } \\
\text { kaempferol-3-rutinoside (8.1) }\end{array}$ \\
\hline Tomato & $\begin{array}{c}\text { Chlorogenic acid (2.4), myricetin-3-O-glucoside }(0.3) \text {, rutin (1.3), } \\
\text { kaempferol-3-O-glucoside }(0.1) \text {, quercetin }(0.4)\end{array}$ \\
\hline Celery & $\begin{array}{l}\text { Chlorogenic acid (75.3), quercetin-3, } 4^{\prime} \text {-diglucoside (2.3), rutin (368.9), } \\
\text { quercetin-3-beta-glucoside (5.7), kaempferol-3-rutinoside (22.1) }\end{array}$ \\
\hline Radish & Catechin (2.7) \\
\hline
\end{tabular}

We can observe that quercetin, rutin, and glucoside derivatives are from the major polyphenols present in grapes, strawberries, raspberries, beans, tomatoes, and celery. There is considerable evidence from in vitro studies, animal models, and clinical studies supporting the concept that several polyphenols have powerful anti-oxidant [5] and antitumor properties (cell cycle delay, apoptosis induction, metastasis prevention) [6].

This review concerns: (a) The benefits of the Mediterranean diet based on cohorts and case-control studies for prevention of cancer, cardiovascular risk, and cognition; (b) polyphenols as major disease-preventing components and analyses of the roles of these molecules; (c) the metabolism of polyphenols and the importance of the microbiome in generating active compounds; (d) the intestine antitumor efficiency and the mechanisms of these polyphenols and the use of nanoformulations; (e) the future developments of the Mediterranean diet, which is growing over the world, and the interest in nanoformulation supplements based on this diet.

\section{Benefits of the Mediterranean Diet in Preventing or Treating Cancer}

Taking France as an example, since 2004 cancer (152,708 death) is ahead of cardiovascular disease (147,323 death) as the leading cause of mortality. Interestingly, numerous works illustrate the benefits of the Mediterranean diet in preventing cancer and other important illnesses.

In cancer, the analysis of an Italian cohort of breast cancer suggests that the adoption of a strict Mediterranean diet is associated with a decrease of $30-50 \%$ of the incidence of its development. In addition, relapse and mortality in breast cancer is decreased in patients that have a daily exercise of at least $30 \mathrm{~min} /$ day [7]. A case-control study performed in Catania, Italy, on 338 patients diagnosed with colorectal cancer (CRC) compared to 676 subjects with no apparent clinical syndrome, showed a significant association between the adoption of a strict Mediterranean diet and a decrease of the relative risk of developing CRC, with an odds ratio of 0.46 [8]. In head and neck cancer, analysis of a sample of 168 subjects (100 controls and 68 cases) showed that medium-high adherence to the Mediterranean diet was associated with a lower risk of developing head and neck cancer (OR, 0.48 [95\% CI: 0.20-1.07], $p=0.052$ ) [9]. Very recently, Melander et al., [10] studied the prevalence of cardiovascular disease and cancer in Mediterranean and the north European middle-aged 
populations. They showed the odds ratio for cancer in Malmö (Sweden) versus Cilento (Italy) was $2.78(1.81-4.27)(p<0.001)$ in inhabitants adjusted for age and sex.

Besides the anti-cancer activity of the Mediterranean diet, other benefits have been reported. A meta-analysis on 18 studies (cohort of 4,172,412 subjects), demonstrated that consumption of the Mediterranean diet led to an $8 \%$ reduction in general mortality and a $10 \%$ decrease in the risk of development of cardiovascular illness [11]. Knowing that decreased telomere length at the chromosome ends and increased shortening rate of telomeres are aging biomarkers, a study conducted on 217 elderly reported an association between leukocyte telomere length, telomerase activity as well as benefits on health status. In subjects with a strict adherence to the Mediterranean diet, the leucocyte chromosomes showed the greatest length of telomeres $(p=0.003)$ and the highest telomerase enzyme activity $(p=0.013)$ [12]. In addition, an Irish study was conducted on 2621 subjects of an average of 25 years old at the inclusion and who were followed for 30 years, monitoring their food habits. Subjects with good adherence to the Mediterranean diet were $46 \%$ less sensitive to declines in their cognitive capacities, particularly their thought capacities. For 868 participants with strong adherence, $9 \%$ showed low thought capacities while this frequency was $29 \%$ in 798 participants with low adherence to Mediterranean diet [13]. Recently, in relation to the current pandemic situation of COVID-19, flavan-3-ols and dimeric proanthocyanidins have been reported by Zhu et al., to prevent SARS-cov2 infection [14].

In this review, a focus on intestinal cancers has been chosen for two reasons. In France, in 2018, CRC (Figure 1) was the second cause of mortality $(17,117)$ and morbidity $(43,336)$ after breast cancer and lung cancer (men). The intestinal tract is directly exposed to and is the primary absorption/metabolism site for dietary compounds which can be either basic nutrients for energy supply and growth, micronutrients (polyphenols, etc.), and toxins.

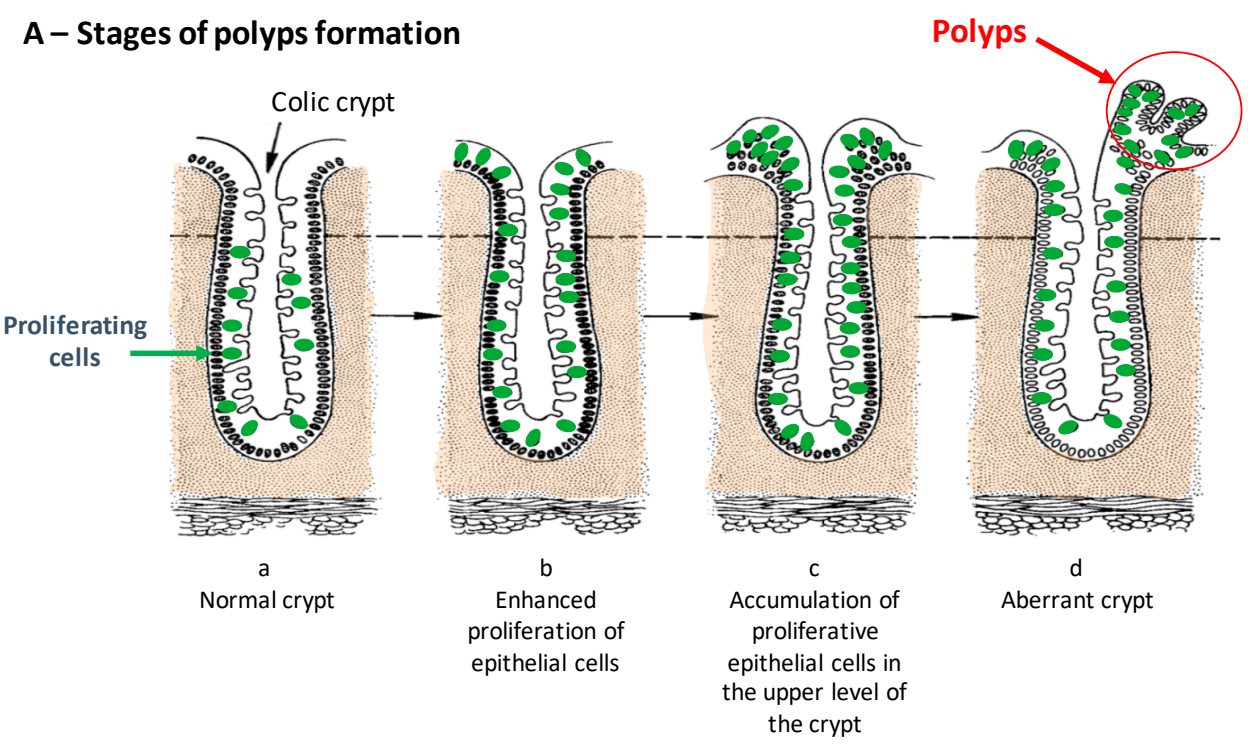

Figure 1. Cont. 


\section{B - Different stages of colic carcinoma}

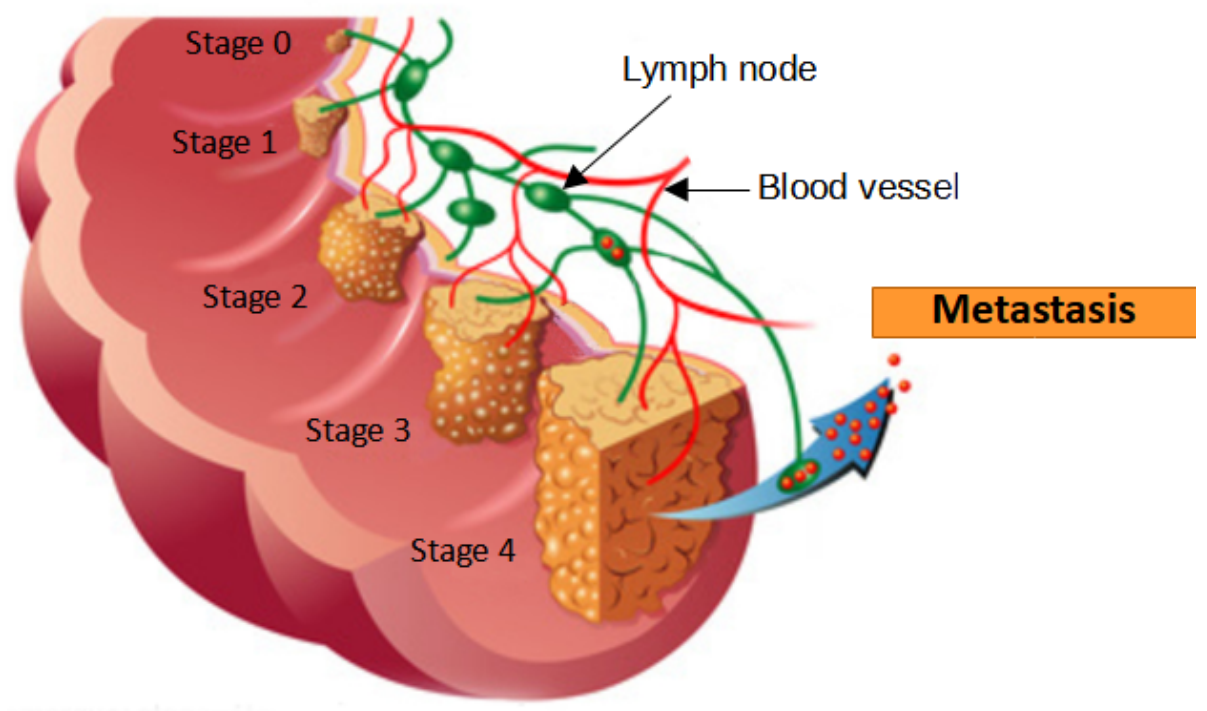

Figure 1. (A) Polyps as precancerous intestinal cancer, (B) colonic carcinogenesis stages. Adapted from the PhD Thesis of Dr F. Mazué (Director of Thesis; Prof. N. Latruffe; https:/ / www.theses.fr/16 5862416, accessed on 7 June 2021).

\section{Key Selected Polyphenols}

From several thousand different polyphenols, we have focused on species present in significant quantities in the plants, fruits, and vegetables present in the Mediterranean diet i.e., apigenin, curcumin, EGCG (Epi Gallo Catechin Gallate), quercetin, resveratrol and rutin (Figure 2). Interesting antitumor properties of these compounds have been reported in the literature [15-17]. We first report the general properties of these polyphenols, their origin, abundance, physico-chemical, and biological properties (Table 3). We will also present the anticancer properties of these selected polyphenols.

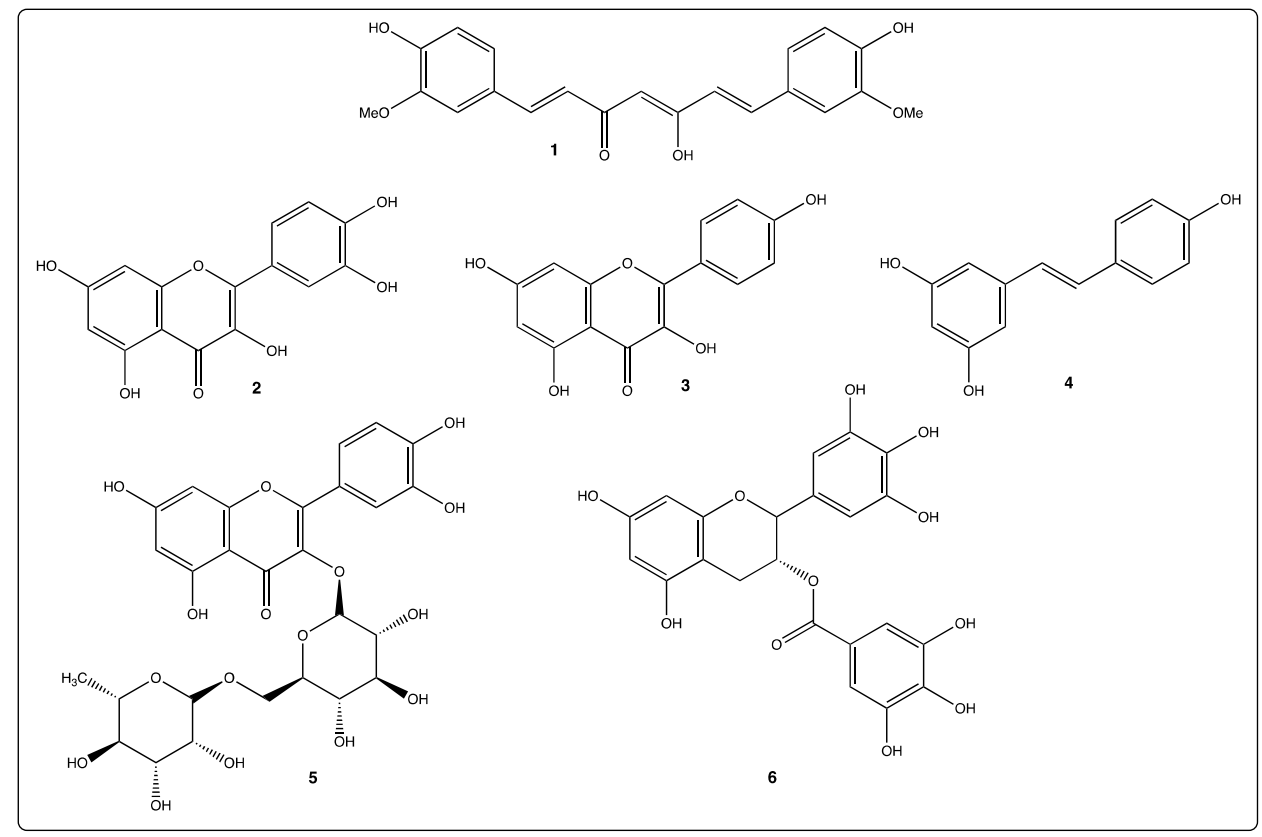

Figure 2. Chemical structures of selected polyphenols: 1: curcumin; 2: quercetin; 3: apigenin; 4: resveratrol; 5: Rutin; 6: EGCG. 
Table 3. Main characteristics of selected polyphenols.

\begin{tabular}{|c|c|c|c|c|}
\hline $\begin{array}{l}\text { Polyphenol } \\
\text { Family }\end{array}$ & $\begin{array}{l}\text { Mol.Formula } \\
\text { Mol. Weight }\end{array}$ & $\begin{array}{l}\text { Water Solubility } \\
(\mathrm{mg} / \mathrm{L})\end{array}$ & $\begin{array}{c}\text { Main Dietary and Geographic } \\
\text { Sources }\end{array}$ & Ref. \\
\hline $\begin{array}{l}\text { 1: Curcumin } \\
\text { Curcuminoid }\end{array}$ & $\begin{array}{c}\mathrm{C}_{21} \mathrm{H}_{20} \mathrm{O}_{6} \\
368.35 \mathrm{~g} / \mathrm{mol}\end{array}$ & $0.125 \mathrm{mg} / \mathrm{L}$ & $\begin{array}{l}\text { Rhizomes of Curcuma longa } \\
\text { (turmeric) India }\end{array}$ & {$[18,19]$} \\
\hline $\begin{array}{l}\text { 2: Quercetin } \\
\text { Flavonoid }\end{array}$ & $\begin{array}{c}\mathrm{C}_{15} \mathrm{H}_{10} \mathrm{O}_{7} \\
302.20 \mathrm{~g} / \mathrm{mol}\end{array}$ & $\begin{array}{c}0.48 \mathrm{mg} / \mathrm{L} \\
\text { (MilliQ water) }\end{array}$ & $\begin{array}{l}\text { Red grape, onion, broccoli, } \\
\text { tomato, lettuce }\end{array}$ & [20-23] \\
\hline $\begin{array}{l}\text { 3: Apigenin } \\
\text { Flavonoid }\end{array}$ & $\begin{array}{c}\mathrm{C}_{15} \mathrm{H}_{10} \mathrm{O}_{5} \\
270.21 \mathrm{~g} / \mathrm{mol}\end{array}$ & $\begin{array}{c}1.43 \mathrm{mg} / \mathrm{L} \\
(\mathrm{pH}=1)\end{array}$ & $\begin{array}{l}\text { Chamomile (Europe, } \\
\text { Western Asia) }\end{array}$ & {$[24,25]$} \\
\hline $\begin{array}{l}\text { 4: Resveratrol } \\
\text { Stilbenoid }\end{array}$ & $\begin{array}{c}\mathrm{C}_{14} \mathrm{H}_{12} \mathrm{O}_{3} \\
228.24 \mathrm{~g} / \mathrm{mol}\end{array}$ & $30 \mathrm{mg} / \mathrm{L}$ & $\begin{array}{c}\text { Grapes and red wine, } \\
\text { Peanuts, blueberries, rhubarb }\end{array}$ & [26-30] \\
\hline $\begin{array}{l}\text { 5: Rutin } \\
\text { Flavonoid }\end{array}$ & $\begin{array}{l}\mathrm{C}_{27} \mathrm{H}_{30} \mathrm{O}_{16} \\
610.44 \mathrm{~g} / \mathrm{mol}\end{array}$ & $130 \mathrm{mg} / \mathrm{L}$ & $\begin{array}{l}\text { Red grape, citrus, apple, fig, } \\
\text { asparagus, onion, mulberry, tea }\end{array}$ & {$[21,31,32]$} \\
\hline $\begin{array}{l}\text { 6: EGCG } \\
\text { Flavonoid }\end{array}$ & $\begin{array}{c}\mathrm{C}_{22} \mathrm{H}_{18} \mathrm{O}_{11} \\
358.32 \mathrm{~g} / \mathrm{mol}\end{array}$ & $5733.12 \mathrm{mg} / \mathrm{L}$ & $\begin{array}{c}\text { Green tea from leaves and buds of } \\
\text { Camellia sinensis Japan, } \\
\text { Chocolate, Red grape }\end{array}$ & [21,33-35] \\
\hline
\end{tabular}

\section{Metabolism and Microbiota Metabolites}

\subsection{Metabolism}

\subsubsection{Apigenin}

Like many polyphenols, apigenin is also present in nature in a glycosylated form and this flavone is at the center of complex metabolic pathways. The apigenin glycoside, after deglycosidation in enterocytes, gives apigenin. In enterocytes, apigenin can then be sulfated, glucuronidated, dehydrogenated, hydrogenated, and hydroxylated; the hydroxylated product can then be methylated and hydroxylated. Apigenin is also a major metabolite of naringin, a flavone present in very large quantities in grapefruit and pomelo. Metabolites profiles of flavonoids are usually obtained with the use of UHPLC-QTOFMS/MS in combination with in silico approach [36].

\subsubsection{Curcumin}

As with all polyphenols, after oral administration, the bioavailability of curcumin is low and the blood levels are reduced relative to those ingested. However, curcumin's resistance to highly acidic $\mathrm{pH}$ is high and it reaches the large intestine without chemical and structural changes [37]. Curcumin is poorly absorbed from the gastrointestinal tract and is extensively metabolized in the enteric and hepatic tract. Glucuronidation of curcumin by beta-glucuronidase is a major metabolic pathway and the glucuronide form of curcumin is found in biological fluids as well as organs and cells of different species (rat, mouse, man). Curcumin can also be sulfated by sulfotransferase to give curcumin sulfate [38]. In hepatocytes and enterocytes, curcumin can also be reduced by various enzymes, including cytochrome P450 enzymes [39]. The products formed, dihydrocurcumin and tetrahydrocurcumin, can in turn be metabolized to glucuronide and sulfate derivatives [37]. Commercial products often contain demethoxycurcumin and bisdemethoxycurcumin, which undergo metabolism similar to that of curcumin [37].

\subsubsection{EGCG}

This polyphenol is essentially absorbed in the intestine and, like all polyphenols, the intestinal flora plays an important role in its metabolism before absorption, for additional biotransformation [40]. EGCG is metabolized by tissue extracts from the small and large intestine, whereas it is only slightly metabolized by tissue extracts from the liver. Since EGCG is poorly absorbed, blood concentrations of EGCG are low and its many derivatives are found in conjugated or unconjugated forms in plasma and urine [41]. 


\subsubsection{Quercetin}

This polyphenol is one of the most studied and its complex metabolism gives rise to several derivatives. Quercetin, which is essentially poorly absorbed in the small intestine, like all polyphenols, supplies metabolites that are produced by biotransformation by the intestinal microbiota and these are further absorbed in the large intestine. The resulting compounds are bioavailable, circulate in the blood as conjugates with glucuronide, methyl, or sulfate groups attached, and are eventually excreted in the urine. At the enterocyte level, several enzymes are involved in providing additional metabolites of quercetin: UDPglucuronosyltransferase (UGT); sulfotransferase (SULT); catechol-O-methyl transferase (COMT); lactase phloridzin hydrolase (LPH); cytosolic $\beta$-glucosidase (CBG) [42]. The resulting derivatives of quercetin are found in plasma and urine [42].

\subsubsection{Resveratrol}

Resveratrol is efficiently absorbed on oral administration, then appears both in plasma, urine, and to a lesser degree, in feces (Figure 3). Concerning its transport, Lançon et al. showed that human hepatic cell uptake of resveratrol involves both carrier-mediated and diffusion-dependent process [43]. In plasma, resveratrol interacts with serum albumin [44]. Furthermore binding properties between resveratrol or other polyphenols and plasma albumin have been determined in the context of consequences for the health protecting effect of dietary plant microcomponents [45]. Recently, Tung et al., reported that polyphenols bind to LDL at biologically relevant concentrations that are protective against heart disease [46].

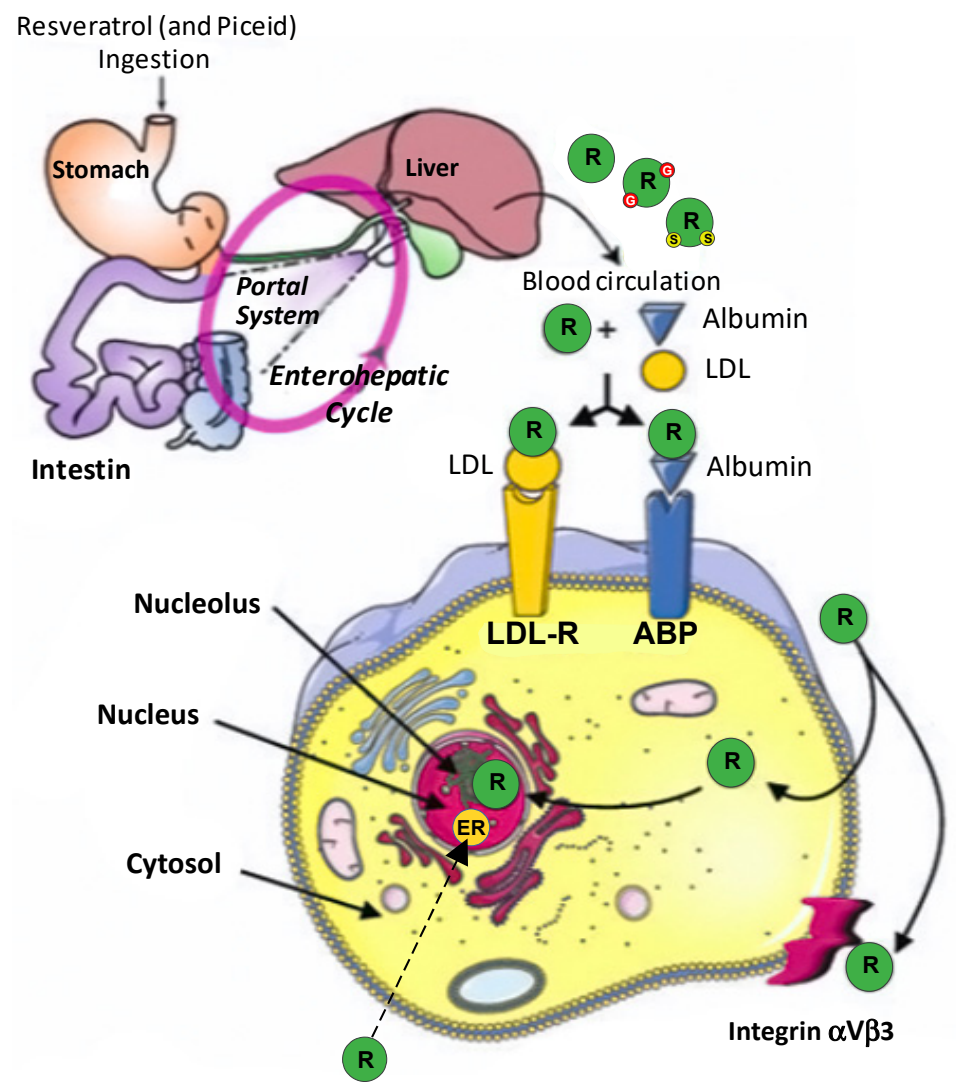

Figure 3. Metabolism of resveratrol. Adapted from Delmas et al., [47]. ER: estrogen-receptor; ABP: albumin-binding protein; LDL: low density lipoprotein; LDL-R: low density lipoprotein-receptor. $\mathbf{R}_{\text {resveratrol; } \Theta^{\ominus}}$ glucurono resveratrol; $s$ s sulfo resveratrol.

Resveratrol metabolism leads to the production of sulfates, glucuronides derivatives, as well as dihydroresveratrol (Figure 3). The nature and quantity of these metabolites may differ between subjects due to inter-individual variability. Once in the bloodstream, 
metabolites can be subjected to phase II metabolism, with further conversions occurring in the liver, where entero-hepatic transport in the bile may result in some recycling back to the small intestine. We have shown in hepatic cells, that resveratrol is highly conjugated after $4 \mathrm{~h}$ of incubation, into mono-(3-sulfate-resveratrol and $4{ }^{\prime}$-sulfate-resveratrol) and disulfate (3,4'-disulfate-resveratrol and 3,5-disulfate-resveratrol) derivatives [47]. Resveratrol can induce its own metabolism by increasing the activity of phase II hepatic detoxifying enzymes [48]. Resveratrol metabolites have a plasma half-life similar to resveratrol aglycone. Despite its low bioavailability, resveratrol in vivo efficacy can be explained by: (i) The back conversion of resveratrol sulfates and glucuronides to resveratrol in target organs such as liver; (ii) the enterohepatic recirculation involving biliary secretion of resveratrol metabolites followed by deconjugation by gut microflora and then reabsorption; (iii) the activities of its metabolites. Two sulfate metabolites show biological activity: Resveratrol-4'-O-sulfate binds the cyclo-oxygenase (COX-1) and inhibits enzyme activity with nearly the same efficacy of resveratrol; resveratrol-3-O-sulfate shows a radical scavenger activity, inhibits $\mathrm{COX}-1$, and is cytotoxic. In contrast to the resveratrol 3-O-sulfate, resveratrol- $4^{\prime}-\mathrm{O}$-sulfate metabolite is less active than resveratrol. Piceatannol $\left(3,5,3^{\prime}, 4^{\prime}\right.$-tetrahydroxystilbene), another analogue of the stilbene family, is a polyphenol found in grapes and other plants; it differs from resveratrol by an additional hydroxyl group at $3^{\prime}$ position of the benzene ring. In humans, piceatannol is produced as a major metabolite of resveratrol by cytochromes CYP1B1 and CYP1A. Piceatannol displays anticancer properties by inducing extrinsic and intrinsic pathways of apoptosis and by blocking cell cycle progression. Trans-resveratrol metabolism by human gut microbiota only generates one metabolite: dihydroresveratrol. The resveratrol derivatives, epsilon-viniferin and their acetates have been studied at the level of their cellular uptake and their antiproliferative effects [49].

\subsection{Microbiota Metabolites}

Microbiomics is a discipline that studies bacterial and viral ecosystems. Microbiomic investigations [50] are promising for addressing the interactions between microorganisms and human cells at the level of organs in which these cells and microorganisms cohabit. At the level of the digestive tract, and the intestine in particular, there are long-lasting interactions between the intestinal flora and the nutrients ingested. At the level of the digestive tract, the activities of the intestinal cells will depend on several epigenetic factors including the microbiota present, as well as nutrients and micronutrients of food origin (Figure 4).

The proper functioning of the cells of the intestinal wall will therefore depend on their interactions with the bacterial ecosystem present and the molecules provided by the food. Food also influences the bacterial ecosystem and the latter can transform certain food molecules by metabolizing them, which is particularly important in the case of polyphenols present in large quantities in the Mediterranean diet [51]. It is currently assumed that the intestinal microbiota of subjects consuming a Mediterranean diet, rich in polyphenols and $\omega 3$ fatty acids, is capable of preventing the appearance of chronic non-transmissible degenerative diseases, such as age-related diseases (cardiovascular diseases, neurodegeneration) and certain types of cancer [52]. For polyphenols, it is well established that understanding their activity is inseparable from understanding their interaction with the microbiota. This includes (i) the biotransformation of polyphenols by the microbiota, which depends on the type of bacteria present, and (ii) the ability of polyphenols to modulate the profile of the bacterial flora [53]. In humans, the ingestion of dietary polyphenols is associated with prebiotic activity (modification of the intestinal flora and its functions) which leads to the formation of several metabolites derived from polyphenols with a beneficial effect on lipid and carbohydrate metabolism (activation of lipogenesis and glycogenesis), which are deregulated in many diseases including cancers [54]. For phytoestrogens, which are a class of polyphenols with a diphenolic structure similar to $17 \beta$-estradiol, it has been shown that they can be transformed by the microbiota [55]. The same transformation process applies to certain isoflavones, prenylfavonoids, lignans, and stilbenes such as reveratrol [55]. The metabolism of intestinal bacteria can also convert food lignans (a non-flavonoid polypheno- 
lic class found in plant foods) into therapeutically relevant polyphenols (i.e., enterolignans) such as enterolactone and enterodiol [56]. Ellagic tannins (substances from the polyphenol family) from the pomegranate are transformed into urolithin A, a mitophagy-activating polyphenol, which increases the lifespan of the worm Caenorhabditis elegans, running endurance in rodents (rats, mice), and transcription of mitochondrial genes in human muscle tissue [57]. Several studies have also shown that polyphenols, by affecting the composition of the intestinal microbiota, modulate oxidative stress and immune response [58]. In agreement with these observations, red wine extracts administered orally reduced the growth of colorectal tumors (hot tumors: associated with inflammatory infiltrates) in mice by reducing the activation of Tlymphocytes to Th17-positive cells [59].

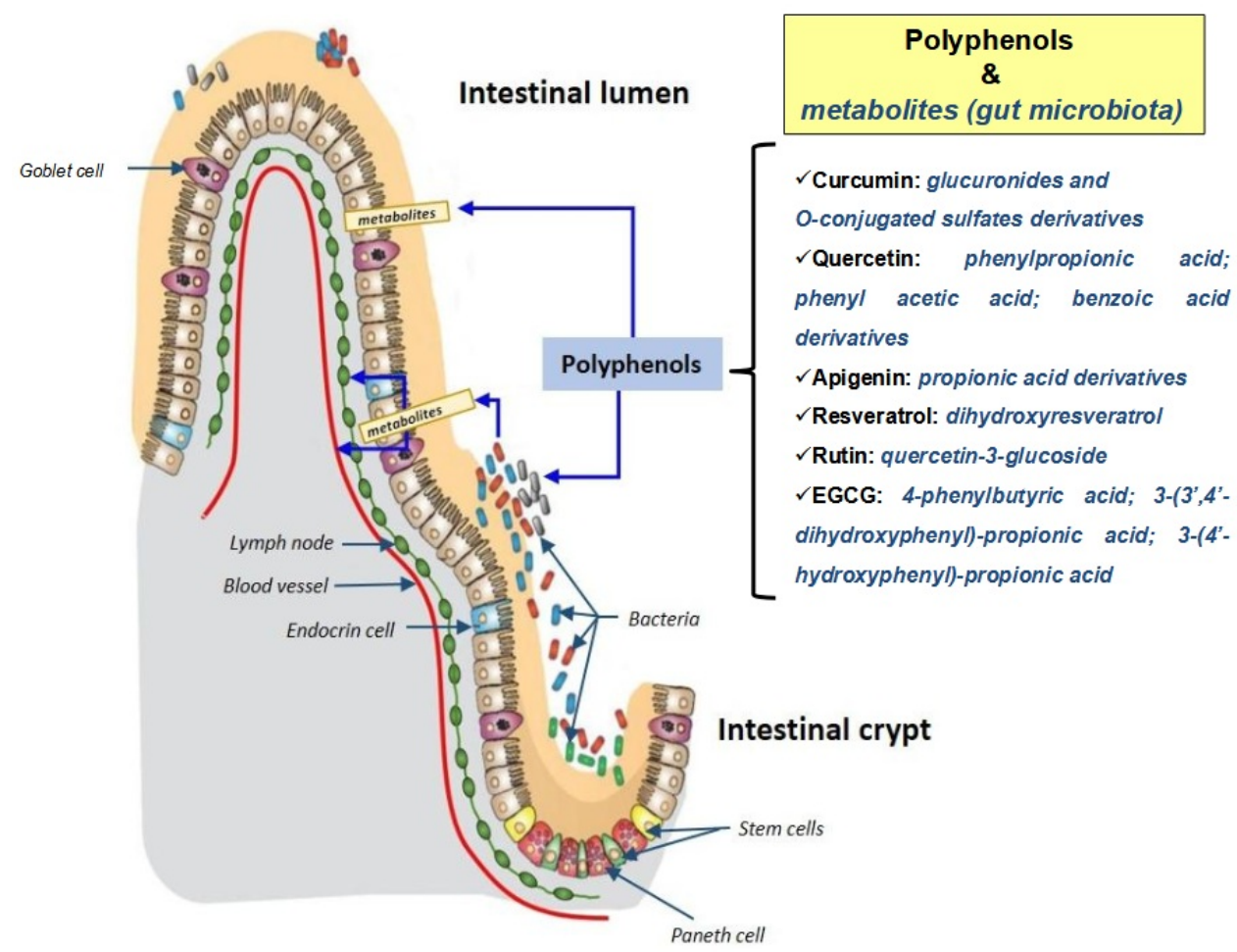

Figure 4. Contribution of the gut microbiota to polyphenol metabolism. The metabolites of polyphenols (curcumin, quercetin, apigenin, resveratrol, rutin and EGCG) produced by the gut microbiota are written in blue.

The mutual interaction of polyphenols with the microbiota is therefore a determining factor in understanding their biological activities. The notion of metabolites generated by the intestinal microbiota must necessarily be taken into account in the case of oral administration. Apigenin, curcumin, EGCG, and quercetin, which are polyphenols associated with the Mediterranean diet, are all subject to transformation by the microbiota.

Apigenin or its glycosides have been shown to be degraded by certain intestinal bacteria into smaller metabolites that can have biological activities [60]. Thus, the capacity of the human intestinal microbiota to convert apigenin-7-glucoside (A7G) has been proven in vitro by incubating A7G with fecal suspensions: apigenin, naringenin, and 3-(4-hydroxyphenyl) propionic acid are formed as the main metabolites [61]. After application of A7G to germ-free rats, apigenin, luteolin, and their conjugates were detected in urine and feces. In human microbiota-associated (HMA) rats (comparatively to germ-free animals), naringenin, eriodictyol, phloretin, 3-(3,4-dihydroxyphenyl)propionic acid, 3-(4hydroxyphenyl)propionic acid, 3-(3-hydroxyphenyl)propionic acid, and 4-hydroxycinnamic acid were also formed in their free and conjugated forms. Furthermore, when apigenin is studied under culture conditions mimicking the ascending colon, it modifies the multipli- 
cation and gene expression of the Enterococcus caccae bacterium, whereas no effect has been observed on Bifidobacterium catenulatum and Lactobacillus rhamnosus G [62].

As for curcumin, which is a lipophilic polyphenol with low systemic bioavailability, it is largely biotransformed by human intestinal microflora to give different metabolites that are easily conjugated to glucuronides and $O$-conjugated sulfate derivatives [63]. It is also suspected that curcumin and its derivatives have direct regulatory effects on the intestinal microbiota. These findings may explain the paradox between the low systemic bioavailability of curcumin and its widely reported pharmacological activities [64].

Epigallocatechin-3-gallate (EGCG), one of the major phenolic compounds in green tea, has versatile bioactivity and exerts a strong anti-cancer effect. EGCG is mainly absorbed in the gut, and the intestinal microbiota plays an essential role in its metabolism prior to absorption [40]. The interaction of green tea phenolic compounds, particularly EGCG, with the intestinal microbiota may play a key role in the health benefits by generating beneficial bioactive compounds. When the metabolic fate of EGCG and its impact on the intestinal microbiota was studied through in vitro fermentation, it was shown by ultra-high performance liquid chromatography and Orbitrap quadrupole hybrid mass spectrometry (UHPLC-Q-Orbitrap-MS), that EGCG is rapidly degraded to a series of metabolites, including 4-phenylbutyric acid, 3-(3', $4^{\prime}$-dihydroxyphenyl)propionic acid and 3-(4'-hydroxyphenyl)propionic acid, by subsequent hydrolysis of the esters, opening of the C-ring, fission of the A-ring, dihydroxylation, and shortening of the aliphatic chain. Microbiome profiling indicated that, compared to negative controls, treatment with EGCG resulted in the stimulation of the beneficial bacteria Bacteroides, Christensenellaceae, and Bifidobacterium, while the growth of pathogenic bacteria Fusobacterium varium, Bilophila, and Enterobacteriaceae was inhibited [65].

Like other polyphenols, quercetin, which is a plant polyphenol widely present in the Mediterranean diet, is metabolized by the microbiota and acts on the composition and activity of the intestinal flora. As with other polyphenols, it is crucial to better understand the impact of the microbiota on quercetin in order to better understand its effects on health [66]. Thus, quercetin is bioaccessible to the microbiota in the colon, which metabolizes it by producing phenylpropanoic acid, phenylacetic acid, and benzoic acid derivatives [67]. In addition, the effects of quercetin have been documented on the intestinal commensal microbes Ruminococcus gauvreauii, Bifidobacterium catenulatum, and Enterococcus caccae [68]. Quercetin does not inhibit the growth of Ruminococcus gauvreauii, it slightly suppresses the growth of Bifidobacterium catenulatum, and moderately inhibits the growth of Enterococcus caccae. Transcriptomic analysis revealed that in response to quercetin, Ruminococcus gauvreauii negatively regulates the expression of genes responsible for protein folding, purine synthesis and metabolism; Bifidobacterium catenulatum increases the expression of the ABC transport pathway, decreases metabolic and cell wall synthesis pathways; Enterococcus caccae upregulates the genes responsible for energy production and metabolism and downregulates the stress response, translation, and sugar transport pathways [68].

Thus, a better understanding of the interactions of polyphenols with the intestinal microbiota will lead to a better knowledge of their biological activities and optimize their use in prevention or treatment of diseases such as cancer. Furthermore, the identification of metabolites resulting from their degradation by the intestinal microbiota may lead to the discovery of new molecules with greater pharmacological activities than the natural molecules from which they are derived.

\section{Antitumor Efficiency}

\subsection{Apigenin}

The Mediterranean diet contains high quantities of flavonoids, a group representing $60 \%$ of natural polyphenols. Apigenin is the most commonly occurring flavonoids found in several dietary constituents [69]. A diet rich in flavonoids may be considered useful to fight cancer development [70]. It has been reported that apigenin is able to suppress cell growth in many types of human cancer cells: leukemia [71], melanoma [72], breast 
cancer [73], bladder cancer [74], thyroid cancer [75], and colonic cancer [76]. Apigenin has multiple anti-cancer effects [69]: anti-proliferation, anti-inflammation, and anti-metastatic activities. It inhibits growth of different types of cancer. Many signaling pathways are involved on the anti-carcinogenic mechanism of apigenin; the best known of which are MAPK, NF-kB, P53, signal transducer, and activator of transcription (STAT3), PI3K/Akt, cyclooxygenase (COX), and Wnt/ $\beta$-catenin pathway [77] (Table 4).

Table 4. Antitumoral effects of apigenin in colorectal cancer.

\begin{tabular}{|c|c|c|c|c|}
\hline \multicolumn{5}{|c|}{ APIGENIN } \\
\hline $\begin{array}{l}\text { Experimental } \\
\text { Models }\end{array}$ & Concentration Range & Biological Response & $\begin{array}{l}\text { Pathway/Genes/Proteins } \\
\text { Involved }\end{array}$ & Refs. \\
\hline \multicolumn{5}{|c|}{ Cells and Cell Lines } \\
\hline HCT-15 & $43.28 \mu \mathrm{M}$ & $\begin{array}{c}\uparrow \text { Cell cytotoxicity } \\
\uparrow \text { Apoptosis } \\
\uparrow \text { Cell cycle arrest G2/M }\end{array}$ & $\uparrow \mathrm{p} 21, \uparrow$ cyclin B1 & [76] \\
\hline SW480 & $40 \mu \mathrm{M}$ & $\begin{array}{c}\downarrow \\
\downarrow \text { Proliferation } \\
\downarrow \text { Invasion } \\
\downarrow \text { Migration } \\
\downarrow \text { Cell migration, } \downarrow \text { Invasion, } \downarrow \\
\text { Metastasis } \\
\downarrow \text { Proliferation }\end{array}$ & $\begin{array}{c}\downarrow \text { Wnt } / \beta \text {-catenin } \\
\downarrow \text { FAK, Src, crk-L, AKT } \\
\downarrow \text { NEDD9 }\end{array}$ & [78] \\
\hline \multirow{3}{*}{ HCT-116 } & & $\begin{array}{c}\downarrow \text { Proliferation, } \downarrow \text { Apoptosis } \downarrow \\
\text { Autophagy }\end{array}$ & $\begin{array}{l}\downarrow \text { Cyclin B1, } \downarrow \text { Cdc } 2, \text { Cdc } 25 c, \\
\uparrow \text { PPAR cleavage, } \uparrow \text { LC3-II }\end{array}$ & [80] \\
\hline & $\begin{array}{c}20 \mu \mathrm{M} \text { and } \\
40 \mu \mathrm{M}\end{array}$ & $\begin{array}{l}\uparrow \text { Autophagy / Apoptosis } \downarrow \text { Cell } \\
\text { grouth, cell cycle arrest G2/M }\end{array}$ & $\downarrow$ PI3K/AKT / Mtor & [81] \\
\hline & $10 \mu \mathrm{M}$ & $\uparrow$ Apoptosis, $\downarrow$ Trascriptional level & $\begin{array}{c}\text { PKC } \delta / \text { ATM kinase, } \downarrow \text { NAG-1, } \\
\downarrow \text { p53, } \downarrow \text { p21 }\end{array}$ & \multirow[t]{2}{*}{ [82] } \\
\hline LoVo & $1-10 \mu \mathrm{M}$ & $\uparrow$ Apoptosis & $\downarrow$ NAG- $1, \downarrow$ p53, $\downarrow$ p21 & \\
\hline DLD-1 & $40 \mu \mathrm{M}$ & $\begin{array}{c}\downarrow \text { Cell migration, } \downarrow \text { Invasion, } \downarrow \\
\text { Migration } \\
\downarrow \text { Cell migration, } \downarrow \text { Invasion, }\end{array}$ & $\begin{array}{c}\downarrow \text { NEDD9, } \downarrow \text { FAK, Src, crk-L, } \\
\text { AKT, } \uparrow \text { TAGLN, } \downarrow \text { MMP-9 } \\
\uparrow \text { TAGLN }, \downarrow \text { MMP-9 }\end{array}$ & $\begin{array}{l}{[79]} \\
{[83]}\end{array}$ \\
\hline HT-29 & $45.96 \mu \mathrm{M}$ & $\begin{array}{l}\uparrow \text { cell cytotoxicity } \\
\uparrow \text { Apoptosis }\end{array}$ & $\uparrow \mathrm{p} 21, \uparrow$ cyclin B1 & [76] \\
\hline \multicolumn{5}{|c|}{ Animal models } \\
\hline \multirow{2}{*}{$\begin{array}{l}\text { Athymic nude } \\
\text { mice }\end{array}$} & $\begin{array}{l}20 \mathrm{mg} / \mathrm{kg} \\
\text { (I.P) }\end{array}$ & \multirow{2}{*}{$\begin{array}{c}\downarrow \text { Cell migration, } \downarrow \text { Invasio } \\
\quad \downarrow \text { proliferation } n \\
\quad \downarrow \text { Angigenesis } \\
\quad \downarrow \text { proliferation }\end{array}$} & $\begin{array}{l}\downarrow \text { FAK, Src, crk-L, AKT } \\
\downarrow \downarrow \text { NEDD9 }\end{array}$ & [79] \\
\hline & $50 \mathrm{mg} / \mathrm{kg}$ (I.P) & & $\downarrow \mathrm{CD}-31, \downarrow \mathrm{Ki}-67$ & [76] \\
\hline $\begin{array}{l}\text { BALB/c-nude } \\
\text { mice }\end{array}$ & $\begin{array}{l}50 \mathrm{mg} / \mathrm{kg} \\
\text { (Per Os) }\end{array}$ & $\begin{array}{c}\downarrow \text { Cell migration, } \downarrow \text { Invasion, } \downarrow \\
\text { Proliferation }\end{array}$ & $\uparrow$ TAGLN,$\downarrow$ MMP-9 & [83] \\
\hline $\begin{array}{l}\mathrm{APCMin} /+ \\
\text { mice }\end{array}$ & $50 \mathrm{mg} / \mathrm{kg}$ (I.P) & $\downarrow$ tumor volume, $\uparrow$ Apoptosis & $\uparrow \mathrm{p} 21, \downarrow \mathrm{p} 53$ & [82] \\
\hline
\end{tabular}

\subsection{Curcumin}

Curcumin acts as anti-inflammatory, anti-oxidant, and antiproliferative agent. It has been recommended for chemopreventive, anti-metastatic, and anti-angiogenic purposes [84]. Several studies have shown that curcumin as an anti-carcinogenetic agent, is used on many type of tumors such as prostate, pancreas, breast, stomach, liver carcinomas, and leukemia [85]. Despite its limited bioavailability observed by oral administration, curcumin modulates several illnesses especially intestinal inflammatory pathologies such as Crohn's disease, necrotizing enterocolitis, and ulcerative colitis [86]. Epidemiological studies have shown that patients with long-term intestinal inflammation present a risk of developing colorectal cancer [87]. Curcumin is taken up by intestinal epithelial cells [88]. 
Curcumin inhibits anti-apoptotic Bcl-2 proteins family in intestinal epithelial cells and stimulates the expression of p53, Bax, procaspases 3, 8, and 9 and the pro-apoptotic Bax protein [89]. Curcumin binds vitamin D receptor present in intestinal epithelial cells involved in the promotion of colon cancer chemopreventing process [90]. Table 5 summarizes the antitumor effects of curcumin in colon cancer, from in vitro and in vivo models and human clinical trials (Table 5).

In vivo studies performed in rats show that curcumin elimination is slower by intravenous (i.v.) administration (44.5 $\mathrm{min}$ ) for a dose of $1 \mathrm{~g} / \mathrm{kg}$ [91], than when orally administered (28.1 $\mathrm{min}$ ) at a dose of $300 \mathrm{mg} / \mathrm{kg}$ [92]. Results from human clinical trials [93], demonstrate that curcumin bioavailability was increased to about 20-fold when combined with piperine. Di Silvestro et al., [94] showed that lipidated curcumin increases its bioavailability.

Table 5. Antitumoral effects of curcumin in colorectal cancer.

\begin{tabular}{|c|c|c|c|c|}
\hline \multicolumn{5}{|c|}{ Curcumin } \\
\hline $\begin{array}{c}\text { Experimental } \\
\text { Models }\end{array}$ & Concentration Range & Biological Response & $\begin{array}{c}\text { Pathway/Genes/Proteins } \\
\text { Involved }\end{array}$ & Refs. \\
\hline \multicolumn{5}{|c|}{ Cells and Cell Lines } \\
\hline \multirow[t]{3}{*}{ HCT-116 } & $10-25 \mu \mathrm{M}$ & $\uparrow$ Apoptosis & $\begin{array}{c}\downarrow \mathrm{AP}-1, \downarrow \text { NF- } \mathrm{BB}, \\
\downarrow \text { MMP-9 }\end{array}$ & [95] \\
\hline & $\begin{array}{l}20 \mu \mathrm{M} \text { with } \\
5-\mathrm{FU}(5 \mu \mathrm{M})\end{array}$ & $\begin{array}{c}\uparrow \text { Cell cycle arrest (S) } \\
\uparrow \text { Apoptosis } \\
\downarrow \text { Cell proliferation }\end{array}$ & $\begin{array}{c}\downarrow \text { caspase-3, } \downarrow \text { caspase- } 8, \downarrow \\
\text { caspase-9, Bax, } \downarrow \text { PARP, } \uparrow \text { Bcl-2 } \\
\downarrow \text { cyclin D1 }\end{array}$ & [96] \\
\hline & $\begin{array}{c}25 \mu \mathrm{M} \text { with Piperine } \\
(7 \mu \mathrm{M})\end{array}$ & $\begin{array}{c}\downarrow \text { Cell proliferation } \\
\uparrow \text { Cell cycle arrest (G2/M } \\
\uparrow \text { Apoptosis }\end{array}$ & $\downarrow$ cyclin D1, $\uparrow$ caspase-3 & [97] \\
\hline HT29 & $41 \mu \mathrm{M}$ & $\begin{array}{c}\downarrow \text { Oxydative stress } \\
\downarrow \text { Cell growth, } \\
\downarrow \text { Invasion, } \\
\downarrow \text { Metastasis }\end{array}$ & $\begin{array}{l}\downarrow \text { NF-E2, } \downarrow \text { Nrf2 } \\
\downarrow \text { Bcl-2, } \downarrow \text { Cyclin D1, } \\
\quad \downarrow \text { IL6, } \downarrow \text { Cox2 }\end{array}$ & [17] \\
\hline HCT-8/5-Fu & $\begin{array}{c}10 \mu \mathrm{M} \text { with } \\
\text { 5-FU (10 mM) }\end{array}$ & $\uparrow$ Apoptosis, & $\uparrow \mathrm{Nrf2}, \uparrow \mathrm{Bcl}-2, \downarrow \mathrm{Bax}$ & [98] \\
\hline \multicolumn{5}{|c|}{ Animal models } \\
\hline \multirow[t]{2}{*}{ C57BL/ 6} & \multirow{2}{*}{$\begin{array}{c}300 \mathrm{mg} / \mathrm{kg} \text { with DSS } \\
(5 \mathrm{mg} / \mathrm{kg}) \text { I.P. }\end{array}$} & $\begin{array}{c}\downarrow \text { Disease activity index } \\
\downarrow \text { neoplasic lesions }\end{array}$ & $\downarrow \beta$-catenin, Cox 2 , iNOS & [99] \\
\hline & & $\uparrow$ Apoptotosis & $\begin{array}{c}\downarrow \text { cyclinD1, } \downarrow \text { cyclinD3, } \uparrow \\
\text { caspase- } 3, \uparrow \text { caspase-7, } \\
\uparrow \text { caspase-9, } \uparrow \text { PARP }\end{array}$ & [92] \\
\hline $\begin{array}{l}\text { Oxaliplatin- } \\
\text { resistant } \\
\text { HCT116- } \\
\text { xenograft }\end{array}$ & $(1 \mathrm{~g} / \mathrm{kg})$ per os & $\uparrow$ Radiosensitivity & $\begin{array}{l}\downarrow \text { NF- } \mathrm{BB}, \downarrow \text { Ki-67, } \\
\quad \downarrow \text { Notch-1 }\end{array}$ & [100] \\
\hline $\begin{array}{l}\text { Orthopically } \\
\text { implanted CRC } \\
\text { tumors (HC116) }\end{array}$ & $(1 \mathrm{~g} / \mathrm{kg})$ per os & $\begin{array}{l}\downarrow \text { Cell growth, } \\
\downarrow \text { Metastasis }\end{array}$ & $\downarrow N F-\kappa B$ & [91] \\
\hline
\end{tabular}

\subsection{EGCG}

Epigallocatechin-3-gallate (EGCG) is a major biologically active component and the most abundant polyphenol from green tea [101]. Its antitumoral activities in colorectal cancer are well documented (Table 6).

Epidemiological investigations and experimental studies have shown that EGCG exerts an important role by its anticancer and cancer chemopreventive properties. It has been observed to suppress breast cancer [101], lung cancer [102], pancreatic cancer [103], 
and liver cancer [104]. In vivo studies have demonstrated an inhibitory effect of EGCG on inflammation and obesity-related colon carcinogenesis in rodent models [105]. Studies have demonstrated that EGCG exerts its inhibitory role in colorectal cancer and its metastasis by suppressing cell proliferation, inducing apoptosis in human CRC cells [106]. EGCG plays a crucial role in obstructing and inhibiting colorectal cancer sphere formation and proliferation, respectively [107]. The possible molecular mechanisms of EGCG in colorectal cancer involve various molecules and signaling pathways [108] (Table 5).

Table 6. Antitumoral effects of EGCG in colorectal cancer.

\begin{tabular}{|c|c|c|c|c|}
\hline \multicolumn{5}{|c|}{ EGCG } \\
\hline $\begin{array}{l}\text { Experimental } \\
\text { Models }\end{array}$ & Concentration Range & Biological Response & $\begin{array}{c}\text { Pathway/Genes/Proteins } \\
\text { Involved }\end{array}$ & Refs. \\
\hline \multicolumn{5}{|c|}{ Cells and Cell Lines } \\
\hline \multirow{4}{*}{ SW837 } & 50-100 $\mu \mathrm{M}$ & $\downarrow$ Cell growth & $\begin{array}{c}\uparrow \text { IFN- } \gamma, \downarrow \text { IDO, } \\
\quad \downarrow \text { STAT1, } \\
\downarrow \text { JAK/STAT1, } \\
\downarrow \text { ISRE, } \downarrow \text { GAS }\end{array}$ & [109] \\
\hline & $10 \mathrm{ng} / \mathrm{mL}$ & $\begin{array}{l}\downarrow \text { Cell proliferation, } \\
\uparrow \text { Apoptosis }\end{array}$ & $\begin{array}{c}\uparrow \text { CD133, CD44, ALDHA1, } \\
\text { Oct-4, and Nanog, } \\
\downarrow \text { p-GSK3 } \beta, \uparrow \text { GSK3 } \beta, \\
\downarrow \text { Wnt, } \downarrow \beta \text {-catenin, } \downarrow \text { Cyclin D1, } \downarrow \\
\text { PCNA, } \downarrow \text { Bcl2, } \\
\uparrow \text { Bax, } \uparrow \text { caspases } 3,8 \text { and } 9\end{array}$ & [110] \\
\hline & $10-30 \mu \mathrm{M}$ & $\begin{array}{c}\downarrow \text { Cell growth, } \\
\uparrow \text { Cell cycle arrest }(\mathrm{G} 2 / \mathrm{M}), \\
\downarrow \text { Proliferation, } \\
\downarrow \text { Cell invasion, } \downarrow \text { Cell adhesion, } \\
\uparrow \text { Apoptosis }\end{array}$ & $\begin{array}{c}\downarrow \text { MMP2/9, } \\
\uparrow \text { caspases 3, 8 and 9, } \\
\downarrow \text { EGFR and IGF1R, } \\
\downarrow \text { MEK and ERK, } \\
\downarrow \text { PI3K and AKT, } \downarrow \text { Bad }\end{array}$ & [111] \\
\hline & $35 \mu \mathrm{g} / \mathrm{mL}$ & $\begin{array}{c}\uparrow \text { Cell cycle arrest (G0/G1) } \\
\downarrow \text { Cell proliferation, } \uparrow \text { Apoptosis }\end{array}$ & & [112] \\
\hline \multirow[b]{2}{*}{ LoVo } & $35 \mu \mathrm{g} / \mathrm{mL}$ & $\begin{array}{c}\downarrow \text { Cell proliferation, } \\
\uparrow \text { Apoptosis, } \\
\uparrow \text { Cell cycle arrest (G0/G1) }\end{array}$ & & [112] \\
\hline & $10-30 \mu \mathrm{M}$ & $\begin{array}{c}\downarrow \text { Cell growth, } \\
\uparrow \text { Cell cycle arrest (G2/M), } \\
\downarrow \text { Proliferation, } \\
\downarrow \text { Cell invasion, } \downarrow \text { Cell adhesion, } \\
\uparrow \text { Apoptosis }\end{array}$ & $\begin{array}{c}\downarrow \text { MMP2 and 9, } \\
\uparrow \text { caspases 3,8 and 9, } \\
\downarrow \text { EGFR and IGF1R, } \\
\downarrow \text { MEK and ERK, } \\
\downarrow \text { PI3K and AKT, } \downarrow \text { Bad }\end{array}$ & [111] \\
\hline \multirow{7}{*}{ HT29 } & $35 \mu \mathrm{g} / \mathrm{mL}$ & $\uparrow$ Cell cycle arrest (S) & & [112] \\
\hline & $88 \mu \mathrm{M}$ & & $\uparrow \mathrm{Bip}$ & \\
\hline & $262 \mu \mathrm{M}$ & & $\uparrow p$-eIF $2 \alpha$ & \\
\hline & $190 \mu \mathrm{M} / 88 \mu \mathrm{M}$ & $\uparrow$ ER stress, & $\downarrow$ PERK, ATF4 & [113] \\
\hline & $262 \mu \mathrm{M} / 190 \mu \mathrm{M} / 88 \mu \mathrm{M}$ & $\uparrow$ Apoptosis & $\uparrow \operatorname{IRE} 1 \alpha$ & [113] \\
\hline & $\begin{array}{c}262 \mu \mathrm{M} / 190 \mu \mathrm{M} / 88 \mu \mathrm{M} \\
88 \mu \mathrm{M}\end{array}$ & & $\begin{array}{c}\uparrow \text { Caspases } 3 \text { and } 7 \\
\uparrow \mathrm{TfR}\end{array}$ & \\
\hline & $\begin{array}{c}100 \mu \mathrm{M} \text { (with } 20 \mu \mathrm{M} \\
\text { csplatin } \\
\text { or } 20 \mu \mathrm{M} \text { oxaliplatin) }\end{array}$ & $\begin{array}{l}\downarrow \text { Cell viability, } \\
\uparrow \text { Autophagy }\end{array}$ & $\uparrow$ LC3II, $\downarrow$ IP3K & [113] \\
\hline HCT-8 & $35 \mu \mathrm{g} / \mathrm{mL}$ & $\uparrow$ Cell cycle arrest G2/M & & [112] \\
\hline
\end{tabular}


Table 6. Cont.

\begin{tabular}{|c|c|c|c|c|}
\hline \multicolumn{5}{|c|}{ EGCG } \\
\hline $\begin{array}{l}\text { Experimental } \\
\text { Models }\end{array}$ & Concentration Range & Biological Response & $\begin{array}{c}\text { Pathway/Genes/Proteins } \\
\text { Involved }\end{array}$ & Refs. \\
\hline \multirow{4}{*}{ HCT116 } & $12.5 \mu \mathrm{M}$ & $\begin{array}{c}\uparrow \text { Radiosensitivity, } \\
\uparrow \text { Autophagy and Apoptosis }\end{array}$ & $\begin{array}{l}\uparrow \mathrm{Nrf} 2, \uparrow \mathrm{LC} 3, \\
\uparrow \text { Caspase-9 }\end{array}$ & [114] \\
\hline & $50-100 \mu \mathrm{M}$ & $\downarrow$ Cell proliferation & & [115] \\
\hline & $50-100 \mu \mathrm{M}$ & $\uparrow$ Apoptosis & $\begin{array}{c}\quad \downarrow \text { VEGFR2, } \downarrow \text { AKT, } \\
\downarrow \text { tumor growth, } \downarrow \text { proliferation, } \\
\downarrow \text { migration and } \downarrow \text { angiogenesis }\end{array}$ & [115] \\
\hline & $10-30 \mu \mathrm{M}$ & $\begin{array}{c}\downarrow \text { Cell growth, } \\
\uparrow \text { Cell cycle arrest }(\mathrm{G} 2 / \mathrm{M}), \\
\downarrow \\
\downarrow \text { Proliferation, } \\
\downarrow \text { Cell invasion, } \\
\downarrow \text { Cell adhesion, } \uparrow \text { Apoptosis }\end{array}$ & $\begin{array}{c}\downarrow \text { MMP2 and 9, } \\
\uparrow \text { caspases 3, 8 and 9, } \\
\downarrow \text { EGFR and IGF1R, } \\
\downarrow \text { MEK and ERK, } \\
\downarrow \text { PI3K and AKT, } \downarrow \text { Bad }\end{array}$ & [111] \\
\hline \multirow[b]{2}{*}{ DLD-1, } & $\begin{array}{l}100 \mu \mathrm{M} \text { with }(20 \mu \mathrm{M} \\
\text { cisplatin } \\
\text { or } 20 \mu \mathrm{M} \text { oxaliplatin })\end{array}$ & $\begin{array}{l}\downarrow \text { Cell viability, } \\
\uparrow \text { Autophagy }\end{array}$ & $\uparrow \mathrm{LC} 3 \mathrm{II}, \downarrow$ IP3K & [116] \\
\hline & $10 \mathrm{ng} / \mathrm{mL}$ & $\begin{array}{l}\downarrow \text { Cell proliferation, } \\
\quad \uparrow \text { Apoptosis }\end{array}$ & $\begin{array}{c}\uparrow \text { CD133, CD44, ALDHA1, } \\
\text { Oct- } 4, \text { and Nanog, } \\
\downarrow \text { p-GSK3 } \beta, \uparrow \text { GSK3 } \beta, \downarrow \text { Wnt, } \\
\downarrow \beta \text {-catenin, } \downarrow \text { Cyclin D1, } \downarrow \text { PCNA, } \\
\downarrow \text { Bcl2, } \uparrow \text { Bax }, \uparrow \text { caspases } 3,8 \text { and } 9\end{array}$ & [110] \\
\hline RKO & $50-100 \mu \mathrm{M}$ & $\uparrow$ Apoptosis & $\uparrow \mathrm{p} 38$ & [115] \\
\hline Caco-2 & $10-30 \mu \mathrm{M}$ & $\begin{array}{c}\downarrow \text { Cell growth, } \\
\uparrow \text { Cell cycle arrest G2/M, } \\
\downarrow \text { Proliferation, } \\
\downarrow \text { Cell invasion, } \\
\downarrow \text { Cell adhesion, } \\
\uparrow \text { Apoptosis }\end{array}$ & $\begin{array}{c}\downarrow \text { MMP2 and 9, } \uparrow \text { caspases 3,8 and } \\
9, \downarrow \text { EGFR and IGF1R, } \downarrow \text { MEK and } \\
\text { ERK, } \\
\downarrow \downarrow \text { PI3K and AKT, } \downarrow \text { Bad }\end{array}$ & [111] \\
\hline \multicolumn{5}{|c|}{ Animal Models } \\
\hline Male ICR mice & $\begin{array}{l}0.1 \% \text { with (AOM } 10 \mathrm{mg} / \mathrm{kg} \\
\text { body weight I.P followed } \\
\text { by } 2 \%(w / v) \text { DSS) }\end{array}$ & $\begin{array}{c}\downarrow \text { Weight, } \\
\downarrow \text { Inflammation }\end{array}$ & $\begin{array}{c}\downarrow \text { COX2, } \downarrow \text { mRNA } \\
(\mathrm{TNF} \alpha, \text { IFN } \delta, \text { IL6, IL12, IL18) }\end{array}$ & [105] \\
\hline $\begin{array}{l}\text { Eighty SPF } \\
\text { Wistar rats }\end{array}$ & $\begin{array}{c}200 \mathrm{mg} / \mathrm{kg} \text { with (DMH } 40 \\
\mathrm{mg} / \mathrm{kg} \text {, s.c) }\end{array}$ & $\begin{array}{l}\downarrow \text { Tumor volume, } \\
\uparrow \text { Apoptosis }\end{array}$ & $\begin{array}{c}\downarrow \text { p53, PI3K-Akt, } \\
\downarrow \text { I-kappaB kinase } / \text { NF-kappaB }, \downarrow \\
\text { MAPK }\end{array}$ & [117] \\
\hline
\end{tabular}

\subsection{Quercetin}

Quercetin has been shown to have anti-tumor efficacy against intestinal and colon cancer cells both in vitro and in vivo (Table 7). 
Table 7. Antitumoral effects of quercetin in colorectal cancer.

\begin{tabular}{|c|c|c|c|c|}
\hline \multicolumn{5}{|c|}{ QUERCETIN } \\
\hline $\begin{array}{l}\text { Experimental } \\
\text { Models }\end{array}$ & Concentration Range & Biological Response & $\begin{array}{l}\text { Pathway/Genes/Proteins } \\
\text { Involved }\end{array}$ & Refs. \\
\hline \multicolumn{5}{|c|}{ Cells and cell lines } \\
\hline \multirow{7}{*}{ HT-29 } & $25,50,100 \mu \mathrm{M}$ & Apoptosis & $\begin{array}{c}\downarrow \text { Bcl-2, } \uparrow \text { cleaved caspase- } 3, \uparrow \text { cleaved } \\
\text { PARP }, \downarrow \text { p-Akt }, \downarrow \text { ErbB2 } / \text { ErbB3 proteins }\end{array}$ & [117] \\
\hline & $\begin{array}{c}5-30 \mu \mathrm{g} / \mathrm{mL} \text { (with resveratrol, } \\
\text { 1:1 ratio) }\end{array}$ & $\begin{array}{c}\downarrow \text { Oncogenic } \\
\mu \text { microRNA-27a }\end{array}$ & $\begin{array}{c}\downarrow \mathrm{Sp} 1, \downarrow \mathrm{Sp} 3, \downarrow \mathrm{Sp} 4, \\
\downarrow \text { survivin mRNA and proteins }\end{array}$ & [118] \\
\hline & $50,100,200 \mu \mathrm{M}$ & $\begin{array}{c}\text { Apoptosis } \\
\text { S-phase arrest }\end{array}$ & $\begin{array}{c}\downarrow \text { p-Akt }, \downarrow \text { CSN6, } \downarrow \text { Myc, } \downarrow \text { Bcl-2, } \uparrow \text { p53, } \uparrow \\
\text { Bax proteins }\end{array}$ & [119] \\
\hline & $\begin{array}{c}50 \mu \mathrm{M} \text { (with cisplatin: } \\
10 \mathrm{mg} / \mathrm{L} \text { ) }\end{array}$ & $\begin{array}{l}\uparrow \text { Cisplatin-induced } \\
\text { Apoptosis }\end{array}$ & $\downarrow$ Activation of NF- $\mathrm{KB}$ protein expression & [120] \\
\hline & $30 \mu \mathrm{M}$ & $\begin{array}{l}\uparrow \text { TRAIL-induced } \\
\text { Apoptosis }\end{array}$ & $\begin{array}{l}\text { Redistribution of death receptors DR4 and } \\
\text { DR5 into lipid rafts } \\
\uparrow \text { cleaved caspase- } 3 \text { and } \uparrow \text { cleaved Bid } \\
\text { proteins, } \uparrow \text { release Cyt-C }\end{array}$ & [121] \\
\hline & $50,100 \mu \mathrm{M}$ & $\begin{array}{c}\text { Apoptosis } \\
\text { G1-phase arrest }\end{array}$ & $\uparrow \mathrm{AMPK}, \uparrow \mathrm{p} 53, \uparrow \mathrm{p} 21$ proteins & [122] \\
\hline & $\begin{array}{c}50 \mu \mathrm{M} \\
\text { (with dox: } 250 \mathrm{nM} \text { ) }\end{array}$ & $\begin{array}{l}\uparrow \text { Doxorubicin-induced } \\
\text { cytotoxicity }\end{array}$ & $\begin{array}{l}\downarrow \text { Proliferation, } \uparrow \text { apoptosis, and G2/M } \\
\text { arrest for lower IC50 of Dox }\end{array}$ & [123] \\
\hline \multirow{2}{*}{ Caco-2 } & $5-50 \mu \mathrm{M}$ & $\downarrow$ Cell proliferation & $\downarrow \mathrm{CDC} 6, \downarrow$ CDK4, $\downarrow$ cyclin D1 mRNA & [124] \\
\hline & $5-20 \mu \mathrm{M}$ & $\begin{array}{l}\text { Anti-migration } \\
\text { Anti-invasion }\end{array}$ & $\begin{array}{c}\downarrow \text { MMP- } 2, \downarrow \text { MMP-9, } \downarrow \text { TLR } 4, \downarrow \text { NF- } \mathrm{BB}, \uparrow \\
\text { E-cadherin proteins } \\
\downarrow \text { TNF- } \alpha, \downarrow \text { COX-2, } \downarrow \text { IL-6 production }\end{array}$ & [125] \\
\hline $\begin{array}{c}\text { Caco-2 } \\
\text { and SW-620 }\end{array}$ & $25-100 \mu \mathrm{M}$ & Apoptosis & $\begin{array}{c}\uparrow \mathrm{I} \kappa \mathrm{B}-\alpha, \downarrow \mathrm{p}-\mathrm{I} \kappa \mathrm{B}-\alpha, \downarrow \mathrm{Bcl}-2, \\
\uparrow \text { Bax proteins }\end{array}$ & [126] \\
\hline \multirow[t]{2}{*}{ SW480 } & $20-80 \mu \mathrm{M}$ & Apoptosis & $\begin{array}{c}\downarrow \text { Cyclin D1, } \downarrow \text { survivin mRNA, and } \\
\text { proteins }\end{array}$ & [127] \\
\hline & $10 \mu \mathrm{M}$ & $\begin{array}{c}\text { Apoptosis } \\
\text { S-phase arrest }\end{array}$ & $\downarrow$ EGF receptor phosphorylation & [128] \\
\hline $\begin{array}{l}\text { Colo-320 } \\
\text { and Colo-741 }\end{array}$ & $25 \mu \mathrm{g} / \mathrm{mL}$ & Apoptosis Senescence & $\begin{array}{c}\uparrow \mathrm{p} 16, \uparrow \text { Lamin B1, } \uparrow \text { cyclin B1, } \uparrow \text { Bax }, \downarrow \\
\text { Bcl-2 proteins }\end{array}$ & [129] \\
\hline $\begin{array}{c}\text { CT26 } \\
\text { and MC38 }\end{array}$ & $1-10 \mu \mathrm{M}$ & Anti-metastasis & $\begin{array}{l}\uparrow \text { E-cadherin, } \downarrow \text { N-cadherin, } \\
\downarrow \beta \text {-catenin, } \downarrow \text { snail proteins } \\
\downarrow \text { MMP-2, } \downarrow \text { MMP-9 activities }\end{array}$ & [130] \\
\hline DLD-1 & $10.5 \mu \mathrm{M}$ & Anticarcinogenesis & $\downarrow$ COX-2 transcription & [131] \\
\hline $\begin{array}{l}\mathrm{CO} 115 \\
\text { and HCT15 }\end{array}$ & $\begin{array}{c}12 \mu \mathrm{M} \\
\text { (with 5-FU: } 1 \mu \mathrm{M} \text { ) }\end{array}$ & $\begin{array}{l}\uparrow \text { Fluorouracil-induced } \\
\text { apoptosis }\end{array}$ & $\begin{array}{c}\uparrow \mathrm{p} 53, \uparrow \text { cleaved caspase- } 9, \\
\uparrow \text { cleaved caspase- } 3, \\
\uparrow \text { cleaved PARP, } \downarrow \text { Bcl-2 proteins }\end{array}$ & [132] \\
\hline НСТ8- $\beta 8$ & $50 \mu \mathrm{M}$ & $\downarrow$ Cell proliferation & $\begin{array}{c}\uparrow \mathrm{ER} \beta \mathrm{mRNA}, \uparrow \text { ER-responsive luciferase } \\
\text { activity }\end{array}$ & [133] \\
\hline \multicolumn{5}{|c|}{ Animal models } \\
\hline $\begin{array}{l}\text { HT-29 xenograft } \\
\text { in Balb/C nude } \\
\text { mice }\end{array}$ & $\begin{array}{l}10 \mathrm{mg} / \mathrm{kg} / \mathrm{day} \\
(\mathrm{SC} ; 4 \text { weeks) }\end{array}$ & $\uparrow$ Radiosensitivity & $\begin{array}{c}\downarrow \text { Jagged-1, } \downarrow \text { Notch-1, } \downarrow \text { Hes-1, } \\
\downarrow \text { Presenilin } 1, \downarrow \text { Nicastrin proteins }\end{array}$ & [134] \\
\hline
\end{tabular}

In vitro exposure of colon cancer cells such as HT-29, Caco-2, SW480, Colo-320, and Colo-741 to different concentrations of quercetin $(5-200 \mu \mathrm{M})$, induced apoptosis (indicated by chromatin condensation and internucleosomal DNA fragmentation) through procaspases activation coincident with an alteration in the expression of c-myc, p53, p16 and p21, or by inhibition of NF-kB pathway [129]. Another mechanism supporting the anticarcinogenic effect of quercetin is through downregulation of many cell cycle genes which cause cell cycle arrest, and suppression of tumor cell invasion and migration by regulating the 
expression of matrix metalloproteinases (MMPs), such as $\beta$-catenin [130], which can act as an invasion suppressor, and E-cadherin which is lost during tumor metastasis in association with the epithelial mesenchymal transformation [130]. Quercetin can also influence colon cancer cell proliferation and differentiation by downregulating the expression of cyclin D1 [127] and CDC6 [124]. The anti-inflammatory effect of quercetin at 5-20 $\mu \mathrm{M}$ has also been described in Caco- 2 and DLD-1 cells as a result of inhibition of cyclooxygenase-2 (COX-2) [131] and cytokine expression [130].

Multiple studies confirmed quercetin's effectiveness in reducing tumors in mice and rats, which is consistent with its in vitro effects. Quercetin at $50 \mathrm{mg} / \mathrm{kg} /$ day causes a reduction in tumor numbers in rats treated with 1,2-dimethylhydrazine (DMH) via activating the antioxidant defenses and limiting lipid peroxidation and protein peroxidation [131-136]. In CRC mice, quercetin decreased colon damage and mortality while reducing certain CRC-associated gut bacteria, such as Allobaculum and unclassified Erysipelotrichaceae [137]. Cruz-Correa $\mathrm{M}$ et al. [138], showed that after a mean of 6 months of treatment, a combination of curcumin and quercetin reduced the number and size of polyps in patients with Familial Adenomatous Polyposis without causing any significant toxicity. Although more research is required to fully understand the relationship between quercetin consumption and colon cancer in humans, regarding its bioavailability (that may be affected by the food source) and the presence of other bioactive compounds in foods that can interact with quercetin and modulate tumor risk.

\subsection{Rutin}

Many mechanisms have been suggested to explain the in vitro anti-carcinogenic effects of rutin (Table 8$)$.

Table 8. Antitumoral effects of rutin in colorectal cancer.

\begin{tabular}{|c|c|c|c|c|}
\hline \multicolumn{5}{|c|}{ RUTIN } \\
\hline $\begin{array}{l}\text { Experimental } \\
\text { Models }\end{array}$ & Concentration Range & Biological Response & $\begin{array}{c}\text { Pathway/Genes/Proteins } \\
\text { Involved }\end{array}$ & Refs. \\
\hline \multicolumn{5}{|c|}{ Cells and cell lines } \\
\hline \multirow[b]{2}{*}{ HT-29 } & $100-200 \mu \mathrm{M}$ & Apoptosis & $\begin{array}{c}\uparrow \text { Bax }, \downarrow \text { Bcl- } 2, \uparrow \text { cleaved caspases-3, 8, 9, } \\
\text { cleaved PARP proteins }\end{array}$ & [139] \\
\hline & $\begin{array}{l}39 \mathrm{mM} \text { (with Silibinin: } \\
\quad 76 \mathrm{mM} \text { ) }\end{array}$ & Apoptosis & $\begin{array}{c}\uparrow \mathrm{p} 53, \downarrow \text { Bcl-2, } \uparrow \text { Bax }, \uparrow \text { caspase } 3,8,9 \\
\downarrow \text { NFkB }, \downarrow \text { IKK- } \alpha, \downarrow \text { IKK- } \beta, \\
\uparrow \text { p38MAPK, } \uparrow \text { MK- } 2 \text { proteins } \\
\end{array}$ & [140] \\
\hline \multirow[t]{2}{*}{$\begin{array}{l}\text { HT-29 } \\
\text { and Caco-2 }\end{array}$} & $25-200 \mu \mathrm{M}$ & $\begin{array}{l}\downarrow \text { Cell adhesion and } \\
\quad \text { Migration }\end{array}$ & $\begin{array}{c}\downarrow \text { ROS level, impairing attachment to } \\
\text { fibronectin, disrupting cell-ECM } \\
\text { interactions }\end{array}$ & [141] \\
\hline & $136 \mu \mathrm{M}$ & $\downarrow$ Cell proliferation & $\downarrow$ Growth potency & [142] \\
\hline \multicolumn{5}{|c|}{ Animal models } \\
\hline $\begin{array}{l}\text { SW480 xenograft in } \\
\text { nude mice }\end{array}$ & $\begin{array}{l}1-20 \mathrm{mg} / \mathrm{kg} / \text { day (I.P; } \\
32 \text { days) }\end{array}$ & $\begin{array}{c}\text { Anti-tumor } \\
\text { Anti-angiogenesis }\end{array}$ & $\begin{array}{l}\uparrow \text { Mean survival time, } \downarrow \text { tumor volume, } \\
\text { and weight, } \downarrow \text { VEGF levels in serum }\end{array}$ & [143] \\
\hline $\begin{array}{l}\text { MTX-treated Wistar } \\
\text { rats (Intestinal } \\
\text { inflammation) }\end{array}$ & $\begin{array}{c}50,100 \mathrm{mg} / \mathrm{kg} / \text { day (I.P; } \\
1 \text { week) }\end{array}$ & $\begin{array}{l}\downarrow \text { Oxidative stress } \\
\downarrow \text { Inflammation }\end{array}$ & $\begin{array}{c}\downarrow \text { COX-1, } \downarrow \text { COX-2, and } \downarrow 15 \text { LOX } \\
\text { enzymatic activities, restoration of MDA, } \\
\text { protein carbonyl, SOD, GSH levels, and } \\
\text { catalase activity, } \downarrow \text { free acidity and total } \\
\text { acidity }\end{array}$ & [144] \\
\hline $\begin{array}{l}\text { 5-FU-treated Swiss } \\
\text { mice (Intestinal } \\
\text { Mucositis) }\end{array}$ & $\begin{array}{c}50-200 \mathrm{mg} / \mathrm{kg} / \text { day (Per os; } \\
3 \text { days) }\end{array}$ & $\begin{array}{l}\downarrow \text { Oxidative stress } \\
\downarrow \text { Inflammation }\end{array}$ & $\begin{array}{c}\downarrow \text { MDA, } \uparrow \text { GSH concentrations, } \\
\downarrow \text { MPO activity, } \downarrow \text { intestinal mastocytosis, } \\
\downarrow \text { COX-2 proteins }\end{array}$ & [145] \\
\hline $\begin{array}{l}\text { DSS-treated ICR } \\
\text { mice (Colitis) }\end{array}$ & $\begin{array}{c}0.6-6 \text { mg/day (Per os; } \\
2 \text { weeks) }\end{array}$ & $\downarrow$ Inflammation & $\downarrow$ IL-1 $\beta, \downarrow$ IL- $6, \downarrow$ GM-CSF, $\downarrow$ iNOS mRNA & [146] \\
\hline
\end{tabular}


Rutin induces apoptosis (increase in the levels of proteins associated with apoptotic cell death: phospho-Bad, cleaved caspase 3, and cleaved PARP) and inhibits cell proliferation and adhesion (disrupting cell-extracellular matrix interactions) in HT-29, Caco-2, and HCT116 cells at concentrations ranging from 25 to $1000 \mu \mathrm{M}$ [140]. When Caco-2 cells were exposed to rutin (over $1000 \mu \mathrm{M}$ ), the antiproliferative effects of 5-fluorouracil (5FU) and oxaliplatin were enhanced and the potential side effects of these drugs were decreased, suggesting that rutin may have chemopreventive and chemotherapeutic effects on colon cancer. In dextran sulfate sodium (DSS) chemically induced mouse model of colitis, $6 \mathrm{mg} /$ day of rutin suppressed the induction of pro-inflammatory cytokines, resulting in improved symptoms [146]. Another study showed that the administration of rutin (50, $100 \mathrm{mg} / \mathrm{kg} /$ day) offered an extensive protection against methotrexate (MTX)-induced intestinal lesions in rats [144]. This may be due to rutin's anti-inflammatory activities (inhibition of COX-1, COX-2, and 15 LOX enzymatic activity) and free radical scavenging properties (restoration of MDA, protein carbonyl, SOD, GSH levels, and catalase activity).

\subsection{Resveratrol}

Cancer chemopreventive activity of resveratrol, a natural product derived from grapes was first reported by Jang et al. [147]. A review on cancer prevention potential of resveratrol has been recently published [148] and includes: case-control trials (resveratrol and breast cancer risk [149]); clinical studies (clinical pharmacology of resveratrol and its metabolites in colorectal cancer patients $[150,151]$. In vivo studies reported the antitumor effect of resveratrol on the development of spontaneous mammary tumors in HER-2/neu transgenic mice [152]), the impact of metastasis [153], the effect of resveratrol metabolites [154], and targets and mechanistic aspects [155].

Resveratrol shows all of the antiproliferative and pro-apoptotic properties necessary to be an antitumor agent [156]. Conversely, P-glycoprotein 1 affects chemoactivities of resveratrol against human colorectal cancer cell [157]. After cell exposure, resveratrol is accumulated in lipid rafts, which is the first step for endosome formation and triggers apoptosis [158]. Signaling molecules and transcription factors involved in the cell cancer promotion or prevention are sensitive to resveratrol: PPAR, PGC1 $\alpha, \mathrm{NF}-\mathrm{kB}, \mathrm{NRF} 1,2, \mathrm{p} 53$. Nuclear cell cycle components, phosphatases, and cyclins are targets of resveratrol [148].

Resveratrol modulates both oncogenic miRNAs and the expression of tumor-suppressor miRNAs. In SW480 colon cancer cell line, resveratrol treatment decreases the levels of several oncogenic miRNAs targeting genes encoding tumor suppressors and effectors of TGF $\beta$ signaling pathway, while increasing the levels of miR-663. While upregulating several components of the TGF $\beta$ signaling pathway, resveratrol decreases the transcriptional activity of SMADs, the main effectors of the canonical TGF $\beta$ pathway [159].

Resveratrol inhibits human leiomyoma (a benign smooth muscle tumor) cell proliferation via crosstalk between integrin $\alpha \mathrm{v} \beta 3$ and IGF-1R [160].

Levi et al. [149] analyzed the relationship between dietary intake of resveratrol and breast cancer risk from a case-control study, conducted between 1993 and 2003 in the Swiss Canton of Vaud, on 369 cases and 602 controls. A significant inverse association was observed for resveratrol from grapes ( $\mathrm{OR}=0.64$ and 0.55$)$, but not from wine, suggesting that daily p.o. doses of resveratrol at 0.5 or $1.0 \mathrm{~g}$ produce levels in the human gastrointestinal tract in the order of magnitude sufficient to elicit anticarcinogenic effects.

\subsection{Synergistic Effects of Polyphenol Mixtures}

While these effects are mostly obtained in vitro or in small laboratory animals at concentrations that are too high to be compatible with its in vivo low availability, resveratrol can slow down tumor progression in numerous cancer types, for instance blood [161], breast [162], cardiac [163], colon [164], glioma [165], lung [166], melanoma [167], and prostate [168]. As resveratrol is not cytotoxic it can be used as food supplement at high concentrations compatible with significant plasma levels. Moreover, the synergistic effects of other food polyphenols [169], and the fact that resveratrol plasma metabolites also 
exhibit antiproliferative activities, is relevant for diet-dependent cancer prevention [154]. Interestingly, Mazue et al. reported protective effects of red wine extract in rat colon carcinogenesis [170].

\section{Perspectives}

\subsection{Improvements}

The health benefits of Mediterranean diet are now well established. To go further, the goal would be to expand this diet over the world in order to benefit more and more populations. This is a question of public health which needs to be relayed by the media. On the other hand, comparable polyphenols-rich diets are also observed in non-Mediterranean coastal regions at the same latitude, with analogous cooking and eating habits. Besides this, more experimental approaches are needed, especially at the preclinical and clinical studies (case-control studies) and information provided from cohorts. A better knowledge of the possible synergies between single polyphenols in mixtures with other nutrients should be accomplished. We may also pay attention to the influence of immune system in cancer prevention under a Mediterranean diet. Related to the role of microbiome, the following question should be addressed: is there any feedback between the dietary polyphenolmodification of the microbiome ecosystem to the cancer immune defense dependency, or from the gut (second brain) to the central nervous system? Indeed, polyphenol-microbiota interactions have led to reconsideration of the gut-brain axis, initially revealed by the capacity of certain enteric nerve cells to secrete serotonin (5-hydroxytryptamine) involved at the brain level in the control of behavior, mood, and anxiety [171]. Several studies highlight the intervention of the polyphenol-microbiota not only in the occurrence of neuropsychiatric diseases such as schizophrenia [172] but also in metabolic diseases [173]. The intestinal microbiota, by acting on immune, endocrine, and metabolic signaling, is thus able to exert beneficial clinical effects on depression and anxiety [174]. The term psychobiome takes into account the intestinal microbiota by considering its capacity for endocrine substances intervening at the level of several pathways involved in the modulation of neuro-inflammation and in the production of several neurotransmitter precursors [175]. In the context of polyphenol-microbiota interactions, beneficial effects of quercetin as well as curcumin [173], resveratrol [176], and EGCG [41] have been shown. The prevention of anxiety by polyphenols could be beneficial for cancer patients, particularly those with CRC, by providing better psychological support for restrictive therapies.

\subsection{Nanoformulation Improvement}

As described in Section 6.1, the selected polyphenols in this review provide numerous health benefits. However, the problem of their limited uptake from the diet is difficult to solve, because of their poor aqueous solubility and therefore their weak bioavailability. The nanoformulation of bioactive polyphenols may overcome these problems. The benefits of this concept is that it is able to transport and release the biological compound to target sites, without modifying its molecular structure. In addition, the transport of poorly aqueous soluble compounds by a molecular-carrier allows improvement of its bioavailability and therefore, its biological activities [177]. The polyphenols mentioned in this review have been subjected to various forms of nanoformulation, especially resveratrol [178], curcumin [179], quercetin [180], catechins [181], and to a lesser degree, rutin [32] and apigenin [182]. It appears from the literature that in vitro and in vivo bioactivities of nanoformulated polyphenols are generally much better than those obtained with free polyphenols, particularly in the cancer field. While quercetin is poorly soluble in water, the loading of this polyphenol in biodegradable monomethoxy poly(ethyleneglycol)-poly(e-caprolactone micelle (MPEG-PCL) makes possible its complete dispersion in water [183]. Compared to free quercetin, quercetin-loaded MPEG-PCL micelles showed a better in vitro inhibition of growth of CT26 cells with a weaker IC50 and better induction of apoptosis. Similarly, quercetin-loaded MPEG-PCL micelles repressed colon tumor in mice subcutaneous CT26 colon cancer [184]. To further target the biomarkers overexpressed by colon cancer cells 
such as EpCAM (epithelial cell adhesion molecules), nanoparticles may be decorated with specific ligands. Thereby, apigenin-loaded nanoparticles were conjugated with aptamer. The resulting aptamer-conjugated apigenin-loaded nanoparticles were evaluated for their antiproliferative properties toward colon carcinoma cells in vitro, as well as an in vivo colorectal cancer model. Using pharmacokinetic and biodistribution studies, the authors highlighted a greater retention of aptamer-conjugated apigenin-loaded nanoparticle in the colon as compared to free apigenin and aptamer-conjugated empty nanoparticles [182]. Encapsulation of resveratrol in liposomes allows increased aqueous solubility, photostability, and bioavailability of this polyphenol [185]. In addition, resveratrol-loaded liposomes target cancer cells effectively and may show a greater apoptotic activity of HT29 colon cancer cells than free resveratrol [186]. Dual encapsulation involving liposomes and cyclodextrins improves the nanoformulation of resveratrol and its release to HT29 colon cancer cells. Indeed, cyclodextrin stabilizes the polyphenol in its hydrophobic cavity and liposome targets cancer cells [187]. Resveratrol may be encapsulated in PLGA-PEG (poly lactic glycol acid-poly ethylene glycol), a biodegradable and biocompatible polymeric nanoparticle coated with chitosan. The resulting resveratrol-loaded micelles were evaluated in vivo for their anti-proliferative and anti-angiogenic effects in human COLO205-luc colon cancer in xenograft and orthotopic implantation models in athymic mice [188]. In this study, the authors observed decreased tumor growth due to the action of resveratrol-loaded micelles. The anti-angiogenic effect of these resveratrol nanoparticles have been highlighted by the decrease of the $\mathrm{Hb}$ percentage of tumor mass. To explain these promising results, the authors put forward the idea of greater bioavailability of resveratrol-loaded micelles compared to those of free resveratrol.

Curcumin nanoformulation applied to colorectal cancer has been the object of a complete and recent review [189]. Various nanoformulations have been mentioned in particular liposomes, micelles, polymer nanoparticles, cyclodextrins. This review highlighted the advantages of most of the curcumin-loaded nanoparticles but also the limitations of others, such as some cyclodextrin and lipid nanoparticle formulations. The combination of successful results of in vitro and in vivo studies involving curcumin-loaded nanoparticles have allowed the commencement of clinical trials evaluation of the effects of these on intestinal cancer. Synergistic effects between two or more bioactive molecules may afford enhanced activities or complementary activities, more so when these molecules are nanoformulated in the same system. The molecular structures of the co-encapsulated bioactive compounds may be similar or very different from those of the selected polyphenols, as shown in Figure 5. For example, alantolactone (7) is a natural sesquiterpene lactone (Figure 5) isolated from Inula racemose Hook. f. showing antitumor activities through an apoptotic mechanism [190]. The combination of quercetin and alantolactone into micelles allowed induction of immunogenic cell death in microsatellite-stable CRC [191]. Chrysin (8), a natural flavone whose structure is similar to that of quercetin or apigenin (Figure 5) provides multiple properties including anti-tumor activities [192]. Thus, evaluation of activity of curcumin-chrysin loaded in PLGA-PEG nanoparticles toward Caco-2 cancer cells has shown a greater efficiency than either of the individual compounds: a quicker killing of cancer cells and a more efficient suppression of hTERT expression [193]. Piperine (9), an alkaloid isolated from black and long peppers (Figure 5), is known for its ability to inhibit proliferation of HT-29 colon carcinoma cells [194]. The synergistic effect of curcumin and piperine (non-nanoformulated) has been demonstrated in an in vivo experiment against hepatocellular carcinoma in rats [195]. The co-encapsulation in emulsomes of these both bioactive compounds confirmed their synergistic benefits toward HT116 colorectal cancer cells [97]. 


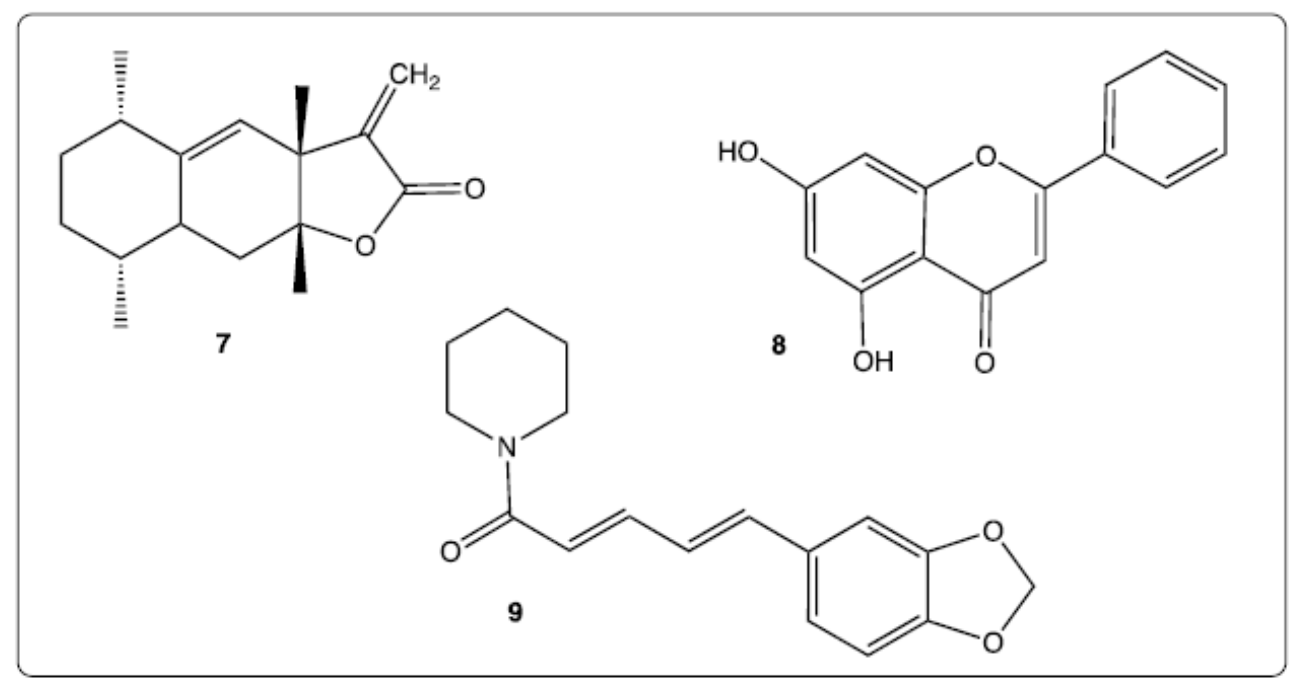

Figure 5. Chemical structures of co-encapsulated compounds: alantolactone (7), chrysin (8), piperine (9).

\subsection{Future Prospects}

Polyphenols may be absorbed by humans via the Mediterranean diet and in this condition, may play a preventative role against cancers and other diseases. To strengthen this prevention, the intake of polyphenols in the form of food supplements has been developed and some of these are widely marketed. In this field, the use of nanotechnology is an attractive concept. In a complete and interesting review, D.D. Milincic et al., reported various polyphenol nanoformulations applied in food industry [196]. The authors highlighted advantages of nanotechnology in preserving healthy benefits of the bioactive compounds, especially stability, anti-oxidant properties, and intestinal bioavailability. However, they warned about an uncontrolled consumption of polyphenols which can lead to harmful effects in humans, because these compounds at high doses may promote pro-oxidant effects [197]. In addition, polyphenols at high doses can chelate bio-elements and decrease their absorption by the gastrointestinal tract [198]. Indeed, nanoparticle toxicity must be not neglected and the use of nanoformulated polyphenols for therapeutic applications and food supplements requires further safety-risk assessments.

In conclusion, the future development of nanoformulations should provide new properties of dietary polyphenols, to benefit cancer prevention, especially due to increased polyphenols cell absorption, plasma level, and targeting.

Author Contributions: Conceptualization, N.L.; investigation: A.Y., A.N., G.L. and D.V.-F.; writing original draft, A.N., G.L., D.V.-F., A.Y. and N.L.; formal analysis, G.L., A.Y., A.N., D.V.-F. and N.L. Scientific additive of dietary polyphenols, and English correction, J.J.M. All authors have read and agreed to the published version of the manuscript.

Funding: This work was funded by Université de Bourgogne and by CNRS (Dijon, France). This work was also supported by the Council of Bourgogne Franche-Comté (MEDICTA project).

Institutional Review Board Statement: Not applicable.

Informed Consent Statement: Not applicable.

Data Availability Statement: No new data were created or analyzed in this study. Data sharing is not applicable to this article.

Acknowledgments: The authors would like to thank the association "Mediterranean Nutrition and Health (NMS: Nutrition Méditerranéenne \& Santé)". A.Y. received financial support from NMS and awarded the NMS prize in 2019. A.N. is currently post-doc fellow in the laboratory after granting at in cotutelle with the University of Burgundy and the University of Tunis El Manar (Tunis, Tunisia). We also thank the UNESCO Chair, wine culture and tradition, Dijon, for its continuous interest. 
Conflicts of Interest: The authors declare no conflict of interest.

\section{Abbreviations}

5-FU: 5-FluoroUracil; ACC: Acetyl-CoA Carboxylase; Akt: Protein kinase B; ALDH1A1: ALdehyde DeHydrogenase 1 family member A1; AMPK: 5' AMP-activated Protein Kinase; AOM: AzOxyMethane; AP-1: Activator Protein 1; ATF4: Activating Transcription Factor 4; Bad: Bcl-2 associated agonist of cell death; Bax: Bcl-2- associated X protein; Bcl-2: B-cell lymphoma-2; Bid: BH3 interacting domain death agonist; BIP: Binding Immunoglobulin Protein; BrdU: BromodeoxyUridine; CDC6: Cell Division Cycle 6; CDK4: Cyclin-Dependent Kinase 4; COX: CycloOXygenase; COX-2: CycloOXygenase2; CSN: Constitutive photomorphogenesis 9 Signalosome; Cyt-C: Cytochrome c; DMH: 1,2-DiMethylHydrazine; DSS: Dextran Sulfate Sodium; ECM: ExtraCellular Matrix; EGF: Epidermal Growth Factor; EGFR: Epidermal Growth Factor Receptor; EpCAM: Epithelial Cell Adhesion Molecules; ErbB2/ErbB3: Epidermal growth factor receptors; ERK: Extracellular Signal Regulated Kinases; ERß: Estrogen Receptor beta; Fabp2: Fatty acid-binding protein 2; FAK: Focal Adhesion Kinase; FAP: Familial Adenomatous Polyposis; FtH: Ferritin receptor; GAS: Growth Arrest-Specific protein; GM-CSF: Granulocyte-Macrophage Colony- Stimulating Factor ; Gpt: Glutamic-pyruvic transaminase; GSH: Glutathione ; Hes1: Hairy and enhancer of split-1; Hmgcs2: 3-Hydroxy-3-methylglutaryl-CoA synthase 2; hTERT: human TElomerase Reverse Transcriptase; IDO: Indoleamine 2,3-DiOxygenase;IFN$\gamma$ : InterFeroN- gamma; IGF1R: Insulin like Growth Factor 1 Receptor; IKK: Inhibitory- $\mathrm{KB}$ Kinase; IL-1 $\beta$ : InterLeukin 1 beta; IL-6: InterLeukin 6; iNOS: inducible Nitric Oxide Synthase; IRE1 $\alpha$ : Inositol-Requiring Enzyme 1; ISRE: Interferon-Stimulated Response Element; IкB- $\alpha$ : Inhibitor of nuclear factor kappa B; JAK: JAnus Kinase; LC3-II: Light Chain 3-II; LOX: LipOXygenase; MAPK: Mitogen-Activated Protein Kinase; MDA: MalonDiAldehyde; MEK: MAP/ERK kinase-1; MK-2: MAPK-activated protein Kinase-2; MMP: Matrix MetalloProteinase; MP 2/9: Matrix MetalloProteinases 2/9; MPEG-PCL: Monomethoxy Poly(EthyleneGlycol)-Poly(e-CaproLactone) micelle; MPO: MyeloPerOxidase ; MTX: MethoTreXate; NAG-1: NSAID Activated Gene; NANOG: NANOG homeobox; NEDD9: Neural precursor cell Expressed Developmentally Down-regulated protein 9; NF-E2/Nuclear Factor, Erythroid 2; NF-кB: Nuclear Factor kappa B; Nrf2: Nuclear-related factor 2; Oct-4: Octamer-binding transcription factor 4; p53: protein 53; PARP: Poly (ADPRibose) Polymerase; PCNA: Proliferating Cell Nuclear Antigen; $p$-eIF2 $\alpha$ : phosphorylation of eukaryotic Initiation Factor- $2 \alpha$; PERK: PKR-like ER protein Kinase; $p$-GSK3 $\beta$ : Glycogen Synthase Kinase 3 beta; PI3K: PhosphoInositide 3-Kinase; PLGA-PEG: Poly Lactic GlycolAcid-Poly Ethylene Glycol; PPAR- $\gamma$ : Peroxisome Proliferator-Activated Receptors$\gamma$; ROS: Reactive Oxygen Species; SOD: SuperOxide Dismutase; Sp: Specificity protein transcriptions factors; STAT1: Signal Transducer and Activator of Transcription 1; TAGLN: TrAnsGeLiN; TfR: Transferrin Receptor; TLR4: Toll-Like Receptor 4; TNF alpha: Tumour Necrosis Factor alpha; TRAIL: Tumor-necrosis-factor Related Apoptosis Inducing Ligand; VEGF: Vascular Endothelial Growth Factor; VEGFR2: Vascular Endothelial Growth Factor Receptor 2.

\section{References}

1. Brat, P.; Georgé, S.; Bellamy, A.; Du Chaffaut, L.; Scalbert, A.; Mennen, L.; Arnault, N.; Amiot, M.J. Daily polyphenol intake in France from fruit and vegetables. J. Nutr. 2006, 136, 2368-2373. [CrossRef]

2. Debbabi, M.; Karym, E.M.; Camus, E.; Durand, P.; Cherkaoui-Malki, M.; Prost, M.; Jabrane, A.; Nasser, B.; Hammami, M.; Lizard, G. Etude comparative des profils anti-oxydants et de la composition en polyphénols de fruits et de légumes associés au régime méditerranéen. In Wine, Mediterranean Diet and Health; Latruffe, N., Ed.; EUD: Dijon, France, 2017; pp. 63-70. Available online: eud.u-bourgogne.fr (accessed on 7 June 2021). (In French)

3. Willett, W.C.; Sacks, F.; Trichopoulou, A.; Drescher, G.; Ferro-Luzzi, A.; Helsing, E.; Trichopoulos, D. Mediterranean diet pyramid: A cultural model for healthy eating. Am. J. Clin. Nutr. 1995, 61, 14025-14065. [CrossRef] 
4. Del Rio, D.; Rodriguez-Mateos, A.; Spencer, J.P.; Tognolini, M.; Borges, G.; Crozier, A. Dietary (poly)phenolics in human health: Structures, bioavailability, and evidence of protective effects against chronic diseases. Antioxid. Redox Signal. 2013, 18, 1818-1892. [CrossRef] [PubMed]

5. Schaffer, S.; Eckert, G.P.; Schmitt-Schillig, S.; Müller, W.E. Plant foods and brain aging: A critical appraisal. Forum Nutr. 2006, 59, 86-115. [CrossRef] [PubMed]

6. Gorzynik-Debicka, M.; Przychodzen, P.; Cappello, F.; Alicja Kuban Jankowska, A.; Gammazza, A.M.; Knap, N.; Wozniak, M.; Gorska-Ponikowska, M. Potential Health Benefits of Olive Oil and Plant Polyphenols. Int. J. Mol. Sci. 2018, 19, 686. [CrossRef]

7. Villarini, M.; Lanari, C.; Nucci, D.; Gianfredi, V.; Marzulli, T.; Berrino, F.; Borgo, A.; Bruno, E.; Gargano, G.; Moretti, M.; et al. Community-based participatory research to improve life quality and clinical outcomes of patients with breast cancer (DianaWeb in Umbria pilot study). BMJ Open 2016, 6, e009707. [CrossRef]

8. Grosso, G.; Biondi, A.; Galvano, F.; Mistretta, A.; Marventano, S.; Buscemi, S.; Drago, F.; Basile, F. Factors associated with colorectal cancer in the context of the Mediterranean diet: A case-control study. Nutr. Cancer 2014, 66, 558-565. [CrossRef] [PubMed]

9. Salvatore Benito, A.; Valero Zanuy, M.Á.; Alarza Cano, M.; Ruiz Alonso, A.; Alda Bravo, I.; Rogero Blanco, E.; Maíz Jiménez, M.; León Sanz, M. Adherence to Mediterranean diet: A comparison of patients with head and neck cancer and healthy population. Endocrinol. Diabetes Nutr. 2019, 66, 417-424. [CrossRef]

10. Melander, O.; Antonini, P.; Ottosson, F.; Brunkwall, L.; Gallo, W.; Nilsson, P.M.; Orho-Melander, M.; Pacente, G.; D'Arena, G.; Di Somma, S. Comparison of cardiovascular disease and cancer prevalence between Mediterranean and north European middle-aged populations (The Cilento on Ageing Outcomes Study and The Malmö Offspring Study). Intern. Emerg. Med. 2021. [CrossRef]

11. Sofi, F.; Macchi, C.; Abbate, R.; Gensini, G.F.; Casini, A. Mediterranean diet and health status: An updated meta-analysis and a proposal for a literature-based adherence score. Public Health Nutr. 2014, 17, 2769-2782. [CrossRef]

12. Boccardi, V.; Esposito, A.; Rizzo, M.R.; Marfella, R.; Barbieri, M.; Paolisso, G. Mediterranean diet, telomere maintenance and health status among elderly. PLoS ONE 2013, 8, e62781. [CrossRef] [PubMed]

13. McEvoy, C.T.; Hoang, T.; Sidney, S.; Steffen, L.M.; Jacobs, D.R., Jr.; Shikany, J.M.; Wilkins, J.T.; Yaffe, K. Dietary patterns during adulthood and cognitive performance in midlife: The CARDIA study. Neurology 2019, 92, e1589-e1599. [CrossRef] [PubMed]

14. Zhu, Y.; Xie, D.Y. Docking Characterization and in vitro Inhibitory Activity of Flavan-3-ols and Dimeric Proanthocyanidins against the Main Protease Activity of SARS-Cov-2. Front. Plant Sci. 2020, 11, 601316. [CrossRef] [PubMed]

15. Nadtochiy, S.M.; Redman, E.K. Mediterranean diet and cardioprotection: The role of nitrite, polyunsaturated fatty acids, and polyphenols. Nutrition 2011, 27, 733-744. [CrossRef] [PubMed]

16. Mojzer, E.B.; Hrnčič, M.K.; Škerget, M.; Knez, Z.; Bren, U. Polyphenols: Extraction Methods, Antioxidative Action, Bioavailability and Anticarcinogenic Effects. Molecules 2016, 21, 901. [CrossRef]

17. Estrela, J.M.; Mena, S.; Obrador, E.; Benlloch, M.; Castellano, G.; Salvador, R.; Dellinger, R.W. Polyphenolic Phytochemicals in Cancer Prevention and Therapy: Bioavailability versus Bioefficacy. J. Med. Chem. 2017, 60, 9413-9436. [CrossRef]

18. Hu, Y.; He, Y.; Ji, J.; Zheng, S.; Cheng, Y. Tumor Targeted Curcumin Delivery by Folate-Modified MPEG-PCL Self-Assembly Micelles for Colorectal Cancer Therapy. Int. J. Nanomed. 2020, 15, 1239-1252. [CrossRef] [PubMed]

19. Esatbeyoglu, T.; Huebbe, P.; Ernst, I.M.A.; Chin, D.; Wagner, A.E.; Rimbach, G. Curcumin-From molecule to biological function. Angew. Chem. Int. Ed. 2012, 51, 5308-5332. [CrossRef]

20. Hatahet, T.; Morille, M.; Hommoss, A.; Dorandeu, C.; Muller, R.H.; Begu, S. Dermal quercetin smartCrystals: Formulation development, antioxidant activity and cellular safety. Eur. J. Pharm. Biopharm. 2016, 102, 51-63. [CrossRef]

21. Iacopini, P.; Baldi, M.; Storchi, P.; Sebastiani, L. Catechin, epicatechin, quercetin, rutin and resveratrol in red grape: Content, in vitro antioxidant activity and interactions. J. Food Compos. Anal. 2008, 21, 589-598. [CrossRef]

22. Wein, S.; Beyer, B.; Zimmermann, B.F.; Blank, R.H.; Wolffram, S. Bioavailability of Quercetin from Onion Extracts after Intraruminal Application in Cows. J. Agric. Food Chem. 2018, 66, 10188-10192. [CrossRef]

23. Hertog, M.G.L.; Hollman, P.C.H.; Katan, M.B. Content of potentially anticarcinogenic flavonoids of 28 vegetables and 9 fruits commonly consumed in the Netherlands. J. Agric. Food Chem. 1992, 40, 2379-2383. [CrossRef]

24. Zhang, J.; Liu, D.; Huang, Y.; Gao, Y.; Qian, S. Biopharmaceutics classification and intestinal absorption study of apigenin. Int. J. Pharm. 2012, 436, 311-317. [CrossRef]

25. Shukla, S.; Gupta, S. Apigenin: A Promising Molecule for Cancer Prevention. Pharm. Res. 2010, 27, 962-978. [CrossRef]

26. Balata, G.F.; Essa, E.A.; Shamardl, H.A.; Zaidan, S.H.; Abourehab, M.A.S. Self-emulsifying drug delivery systems as a tool to improve solubility and bioavailability of resveratrol. Drug Des. Dev. Ther. 2016, 10, 117-128. [CrossRef] [PubMed]

27. Hasan, M.M.; Bae, H. An overview of stress-induced resveratrol synthesis in grapes: Perspectives for resveratrol-enriched grape products. Molecules 2017, 22, 294. [CrossRef]

28. Sales, J.M.; Resurreccion, A.V.A. Resveratrol in peanuts. Crit. Rev. Food Sci. Nutr. 2014, 54, 734-770. [CrossRef] [PubMed]

29. Lyons, M.M.; Yu, C.; Toma, R.B.; Cho, S.Y.; Reiboldt, W.; Lee, J.; Van Breemen, R.B. Resveratrol in raw and baked blueberries and bilberries. J. Agric. Food Chem. 2003, 51, 5867-5870. [CrossRef]

30. Raal, A.; Pokk, P.; Arend, A.; Aunapuu, M.; Jogi, J.; Okva, K.; Pussa, T. Trans-resveratrol alone and hydroxystilbenes of rhubarb (Rheum rhaponticum L.) root reduce liver damage induced by chronic ethanol administration: A comparative study in mice. Phytoter. Res. 2009, 23, 525-532. [CrossRef] 
31. Gullon, B.; Lu-Chau, T.A.; Moreira, M.T.; Lema, J.M.; Eibes, G. Rutin: A review on extraction, identification and purification methods, biological activities and approaches to enhance its bioavailability. Trends Food Sci. Technol. 2017, 67, 220-235. [CrossRef]

32. Fahra, A.K.; Gian, R.Y.; Li, H.B.; Wu, D.T.; Atanasov, A.T.; Gul, K.; Zhang, J.R.; Yang, Q.Q.; Corke, H. The anticancer potential of the dietary polyphenol rutin: Current status, challenges, and perspectives. Crit. Rev. Food Sci. Nutr. 2020. [CrossRef]

33. Zhang, X.; Wang, J.; Hu, J.M.; Huang, Y.W.; Wu, X.Y.; Zi, C.T.; Wang, X.J.; Sheng, J. Synthesis and Biological Testing of Novel Glucosylated Epigallocatechin Gallate (EGCG) Derivatives. Molecules 2016, 21, 620. [CrossRef] [PubMed]

34. Fujiki, H. Green tea: Health benefits as cancer preventive for humans. Chem. Record 2005, 5, 119-132. [CrossRef]

35. Arts, I.C.; Hollman, P.C.; Kromhout, D. Chocolate as a source of tea flavonoids. Lancet 1999, 354, 488. [CrossRef]

36. Zhang, Y.; Ouyang, L.; Mai, X.; Wang, H.; Liu, S.; Zeng, H.; Chen, T.; Li, J. Use of UHPLC-QTOF-MS/MS with combination of in silico approach for distributions and metabolites profile of flavonoids after oral administration of Niuhuang Shangqing tablets in rats. J. Chromatogr. B Analyt. Technol. Biomed. Life Sci. 2019, 1114-1115, 55-70. [CrossRef] [PubMed]

37. Di Meo, F.; Margarucci, S.; Galderisi, U.; Crispi, S.; Peluso, G. Curcumin, Gut Microbiota, and Neuroprotection. Nutrients 2019, 11, 2426. [CrossRef]

38. Sharma, R.A.; Steward, W.P.; Gescher, A.J. Pharmacokinetics and pharmacodynamics of curcumin. Adv. Exp. Med. Biol. 2007, 595, 453-470. [CrossRef] [PubMed]

39. Hoehle, S.I.; Pfeiffer, E.; Sólyom, A.M.; Metzler, M. Metabolism of curcuminoids in tissue slices and subcellular fractions from rat liver. J. Agric. Food Chem. 2006, 54, 756-764. [CrossRef] [PubMed]

40. Gan, R.Y.; Li, H.B.; Sui, Z.Q.; Corke, H. Absorption, metabolism, anti-cancer effect and molecular targets of epigallocatechin gallate (EGCG): An updated review. Crit. Rev. Food Sci. Nutr. 2018, 58, 924-941. [CrossRef]

41. Pervin, M.; Unno, K.; Takagaki, A.; Isemura, M.; Nakamura, Y. Function of Green Tea Catechins in the Brain: Epigallocatechin Gallate and its Metabolites. Int. J. Mol. Sci. 2019, 20, 3630. [CrossRef]

42. Almeida, A.F.; Borge, G.I.A.; Piskula, M.; Tudose, A.; Tudoreanu, L.; Valentová, K.; Williamson, G.; Santos, C.N. Bioavailability of Quercetin in Humans with a Focus on Interindividual Variation. Compr. Rev. Food Sci. Food Saf. 2018, 17, 714-731. [CrossRef] [PubMed]

43. Lançon, A.; Delmas, D.; Osman, H.; Thenot, J.P.; Jannin, B.; Latruffe, N. Human hepatic cell uptake of resveratrol: Involvement of both carrier mediaten and diffusion process. Biochem. Biophys. Res. Commun. 2004, 316, 1132-1137. [CrossRef]

44. Jannin, B.; Menzel, M.; Berlot, J.P.; Delmas, D.; Lançon, A.; Latruffe, N. Interactions of resveratrol, a chemopreventive agent, with serum albumin. Biochem. Pharmacol. 2004, 68, 1113-1118. [CrossRef]

45. Latruffe, N.; Menzel, M.; Delmas, D.; Buchet, R.; Lancçon, A. Compared binding properties between resveratrol and of other polyphenols to plasmatic albumin. Consequences for the health protecting effect of dietary plant microcomponents. Molecules 2014, 19, 17066-17077. [CrossRef] [PubMed]

46. Tung, W.C.; Rizzo, B.; Dabbagh, Y.; Saraswat, S.; Romanczyk, M.; Codorniu-Hernández, E.; Rebollido-Rios, R.; Needs, P.W.; Kroon, P.A.; Rakotomanomana, N.; et al. Polyphenols bind to low density lipoprotein at biologically relevant concentrations that are protective for heart disease. Arch. Biochem. Biophys. 2020, 694, 108589. [CrossRef] [PubMed]

47. Delmas, D.; Aires, V.; Limagne, E.; Dutartre, P.; Mazue, F.; Ghiringhelli, F.; Latruffe, N. Transport and stability of Resveratrol condition its biological activity. Ann. N. Y. Acad. Sci. 2011, 1215, 48-59. [CrossRef]

48. Lançon, A.; Hanet, N.; Jannin, B.; Delmas, D.; Heydel, J.M.; Chagnon, M.C.; Lizard, G.; Artur, Y.; Latruffe, N. Resveratrol in human hepatoma HepG2 cells: Metabolism and inducibility of detoxifying enzymes. Drug. Metab. Dispos. 2007, 35, 699-703. [CrossRef]

49. Colin, D.; Lançon, A.; Delmas, D.; Abrossimow, J.; Kahn, E.; Lizard, G.; Jannin, B.; Latruffe, N. Comparative study of the cell uptake and the antiproliferative effects of resveratrol, epsilon-viniferin and their acetates. Biochimie 2008, 90, 1674-1684 [CrossRef]

50. Kumar, P.S. Microbiomics: Were we all wrong before? Periodontology 2000, 85, 8-11. [CrossRef]

51. Hardman, W.E. Diet components can suppress inflammation and reduce cancer risk. Nutr. Res. Pract. 2014, 8, 233-240. [CrossRef]

52. Merra, G.; Noce, A.; Marrone, G.; Cintoni, M.; Tarsitano, M.G.; Capacci, A.; De Lorenzo, A. Influence of Mediterranean Diet on Human Gut Microbiota. Nutrients 2020, 13, 7. [CrossRef]

53. Ozdal, T.; Sela, D.A.; Xiao, J.; Boyacioglu, D.; Chen, F.; Capanoglu, E. The reciprocal interactions between polyphenols and gut microbiota and effects on bioaccessibility. Nutrients 2016, 8, 78. [CrossRef] [PubMed]

54. Koudoufio, M.; Desjardins, Y.; Feldman, F.; Spahis, S.; Delvin, E.; Levy, E. Insight into polyphenol and gut microbiota crosstalk: Are their metabolites the key to understand protective effects against metabolic disorders? Antioxidants 2020, 9, 982. [CrossRef]

55. Seyed Hameed, A.S.; Rawat, P.S.; Meng, X.; Liu, W. Biotransformation of dietary phytoestrogens by gut microbes: A review on bidirectional interaction between phytoestrogen metabolism and gut microbiota. Biotechnol. Adv. 2020, 43, 107576. [CrossRef] [PubMed]

56. Senizza, A.; Rocchetti, G.; Mosele, J.I.; Patrone, V.; Callegari, M.L.; Morelli, L.; Lucini, L. Lignans and gut microbiota: An interplay revealing potential health implications. Molecules 2020, 25, 5709. [CrossRef]

57. Andreux, P.A.; Blanco-Bose, W.; Ryu, D.; Burdet, F.; Ibberson, M.; Aebischer, P.; Auwerx, J.; Singh, A.; Rinsch, C. The mitophagy activator urolithin A is safe and induces a molecular signature of improved mitochondrial and cellular health in humans. Nat. Metab. 2019, 1, 595-603. [CrossRef] 
58. Man, A.W.C.; Zhou, Y.; Xia, N.; Li, H. Involvement of gut microbiota, microbial metabolites and interaction with polyphenol in host immunometabolism. Nutrients 2020, 12, 3054. [CrossRef]

59. Chalons, P.; Courtaut, F.; Limagne, E.; Chalmin, F.; Cantos-Villar, E.; Richard, T.; Auger, C.; Chabert, P.; Schini-Kerth, V.; Ghiringhelli, F.; et al. Red Wine Extract Disrupts Th17 Lymphocyte Differentiation in a Colorectal Cancer Context. Mol. Nutr. Food Res. 2020, 64, e1901286. [CrossRef]

60. Wang, M.; Firrman, J.; Liu, L.; Yam, K. A review on flavonoid apigenin: Dietary intake, adme, antimicrobial effects, and interactions with human gut microbiota. Biomed. Res. Int. 2019, 2019, 7010467. [CrossRef] [PubMed]

61. Hanske, L.; Loh, G.; Sczesny, S.; Blaut, M.; Braune, A. The bioavailability of apigenin-7-glucoside is influenced by human intestinal microbiota in rats. J. Nutr. 2009, 139, 1095-1102. [CrossRef] [PubMed]

62. Wang, M.; Firrman, J.; Zhang, L.; Arango-Argoty, G.; Tomasula, P.; Liu, L.; Xiao, W.; Yam, K. Apigenin impacts the growth of the gut microbiota and alters the gene expression of enterococcus. Molecules 2017, 22, 1292. [CrossRef] [PubMed]

63. Zam, W. Gut microbiota as a prospective therapeutic target for curcumin: A review of mutual influence. J. Nutr. Metab. 2018, 2018, 1367984. [CrossRef]

64. Pluta, R.; Januszewski, S.; Ułamek-Kozioł, M. Mutual two-way interactions of curcumin and gut microbiota. Int. J. Mol. Sci. 2020, 21, 1055. [CrossRef]

65. Liu, Z.; de Bruijn, W.J.C.; Bruins, M.E.; Vincken, J.P. Reciprocal Interactions between Epigallocatechin-3-gallate (EGCG) and Human Gut Microbiota In vitro. J. Agric. Food Chem. 2020, 68, 9804-9815. [CrossRef]

66. Murota, K.; Nakamura, Y.; Uehara, M. Flavonoid metabolism: The interaction of metabolites and gut microbiota. Biosci. Biotechnol. Biochem. 2018, 82, 600-610. [CrossRef]

67. Di Pede, G.; Bresciani, L.; Calani, L.; Petrangolini, G.; Riva, A.; Allegrini, P.; Del Rio, D.; Mena, P. The human microbial metabolism of quercetin in different formulations: An in vitro evaluation. Foods 2020, 9, 1121. [CrossRef] [PubMed]

68. Firrman, J.; Liu, L.; Zhang, L.; Arango Argoty, G.; Wang, M.; Tomasula, P.; Kobori, M.; Pontious, S.; Xiao, W. The effect of quercetin on genetic expression of the commensal gut microbes Bifidobacterium catenulatum, Enterococcus caccae and Ruminococcus gauvreauii. Anaerobe 2016, 42, 130-141. [CrossRef] [PubMed]

69. Birt, D.F.; Mitchell, D.; Gold, B.; Pour, P.; Pinch, H.C. Inhibition of ultraviolet light induced skin carcinogenesis in SKH-1 mice by apigenin, a plant flavonoid. Anticancer Res. 1997, 17, 85-91.

70. Ren, W.; Qiao, Z.; Wang, H.; Zhu, L.; Zhang, L. Flavonoids: Promising anticancer agents. Med. Res. Rev. 2003, 23, 519-534. [CrossRef] [PubMed]

71. Wang, I.K.; Lin-Shiau, S.Y.; Lin, J.K. Induction of apoptosis by apigenin and related flavonoids through cytochrome c release and activation of caspase-9 and caspase-3 in leukaemia HL-60 cells. Eur. J. Cancer 1999, 35, 1517-1525. [CrossRef]

72. Caltagirone, S.; Rossi, C.; Poggi, A.; Ranelletti, F.O.; Natali, P.G.; Brunetti, M.; Aiello, F.B.; Piantelli, M. Flavonoids apigenin and quercetin inhibit melanoma growth and metastatic potential. Int. J. Cancer 2000, 87, 595-600. [CrossRef]

73. Yin, F.; Wakino, S.; Liu, Z.; Kim, S.; Hsueh, W.A.; Collins, A.R.; Van Herle, A.J.; Law, R.E. Troglitazone inhibits growth of MCF-7 breast carcinoma cells by targeting G1 cell cycle regulators. Biochem. Biophys. Res. Commun. 2001, 286, 916-922. [CrossRef]

74. Zhu, Y.; Mao, Y.; Chen, H.; Lin, Y.; Hu, Z.; Wu, J.; Xu, X.; Xu, X.; Qin, J.; Xie, L. Apigenin promotes apoptosis, inhibits invasion and induces cell cycle arrest of T24 human bladder cancer cells. Cancer Cell. Int. 2013, 13, 54. [CrossRef] [PubMed]

75. Zhang, L.; Cheng, X.; Gao, Y.; Zheng, J.; Xu, Q.; Sun, Y.; Guan, H.; Yu, H.; Sun, Z. Apigenin induces autophagic cell death in human papillary thyroid carcinoma BCPAP cells. Food Funct. 2015, 6, 3464-3472. [CrossRef] [PubMed]

76. Banerjee, K.; Banerjee, S.; Mandal, M. Enhanced chemotherapeutic efficacy of apigenin liposomes in colorectal cancer based on flavone-membrane interactions. J. Colloid Interface Sci. 2017, 491, 98-110. [CrossRef]

77. Li, J.; Yu, B.; Deng, P.; Cheng, Y.; Yu, Y.; Kevork, K.; Ramadoss, S.; Ding, X.; Li, X.; Wang, C.Y. KDM3 epigenetically controls tumorigenic potentials of human colorectal cancer stem cells through Wnt/ $\beta$-catenin signalling. Nat. Commun. 2017, 8, 15146. [CrossRef] [PubMed]

78. Xu, M.; Wang, S.; Song, Y.U.; Yao, J.; Huang, K.; Zhu, X. Apigenin suppresses colorectal cancer cell proliferation, migration and invasion via inhibition of the Wnt/ $\beta$-catenin signaling pathway. Oncol. Lett. 2016, 11, 3075-3080. [CrossRef]

79. Dai, J.; Van Wie, P.G.; Fai, L.Y.; Kim, D.; Wang, L.; Poyil, P.; Luo, J.; Zhang, Z. Downregulation of NEDD9 by apigenin suppresses migration, invasion, and metastasis of colorectal cancer cells. Toxicol. Appl. Pharmacol. 2016, 311, 106-112. [CrossRef] [PubMed]

80. Lee, Y.; Sung, B.; Kang, Y.J.; Kim, D.H.; Jang, J.Y.; Hwang, S.Y.; Kim, M.; Lim, H.S.; Yoon, J.H.; Chung, H.Y. Apigenin-induced apoptosis is enhanced by inhibition of autophagy formation in HCT116 human colon cancer cells. Int. J. Oncol. 2014, 44, 1599-1606. [CrossRef]

81. Pandey, M.; Kaur, P.; Shukla, S.; Abbas, A.; Fu, P.; Gupta, S. Plant flavone apigenin inhibits HDAC and remodels chromatin to induce growth arrest and apoptosis in human prostate cancer cells: In vitro and in vivo study. Mol. Carcinog. 2012, 51, 952-962. [CrossRef]

82. Zhong, Y.; Krisanapun, C.; Lee, S.H.; Nualsanit, T.; Sams, C.; Peungvicha, P.; Baek, S.J. Molecular targets of apigenin in colorectal cancer cells: Involvement of p21, NAG-1 and p53. Eur. J. Cancer 2010, 46, 3365-3374. [CrossRef] [PubMed]

83. Chunhua, L.; Donglan, L.; Xiuqiong, F.; Lihua, Z.; Qin, F.; Yawei, L.; Liang, Z.; Ge, W.; Linlin, J.; Ping, Z.; et al. Apigenin up-regulates transgelin and inhibits invasion and migration of colorectal cancer through decreased phosphorylation of AKT. $J$. Nutr. Biochem. 2013, 24, 1766-1775. [CrossRef] 
84. Aggarwal, B.B.; Sung, B. Pharmacological basis for the role of curcumin in chronic diseases: An age-old spice with modern targets. Trends Pharmacol. Sci. 2009, 30, 85-94. [CrossRef] [PubMed]

85. López-Lázaro, M. Anticancer and carcinogenic properties of curcumin: Considerations for its clinical development as a cancer chemopreventive and chemotherapeutic agent. Mol. Nutr. Food Res. 2008, 52, S103-S127. [CrossRef] [PubMed]

86. Aggarwal, B.B.; Harikumar, K.B. Potential therapeutic effects of curcumin, the anti-inflammatory agent, against neurodegenerative, cardiovascular, pulmonary, metabolic, autoimmune and neoplastic diseases. Int. J. Biochem. Cell Biol. 2009, 41, 40-59. [CrossRef]

87. Söderlund, S.; Brandt, L.; Lapidus, A.; Karlén, P.; Broström, O.; Löfberg, R.; Ekbom, A.; Askling, J. Decreasing time-trends of colorectal cancer in a large cohort of patients with inflammatory bowel disease. Gastroenterology 2009, 136, 1561-1567. [CrossRef] [PubMed]

88. Dempe, J.S.; Scheerle, R.K.; Pfeiffer, E.; Metzler, M. Metabolism and permeability of curcumin in cultured Caco-2 cells. Mol. Nutr. Food Res. 2013, 57, 1543-1549. [CrossRef]

89. Kuttan, G.; Kumar, K.B.; Guruvayoorappan, C.; Kuttan, R. Antitumor, anti-invasion, and antimetastatic effects of curcumin. Adv. Exp. Med. Biol. 2007, 595, 173-184. [CrossRef]

90. Bartik, L.; Whitfield, G.K.; Kaczmarska, M.; Lowmiller, C.L.; Moffet, E.W.; Furmick, J.K.; Hernandez, Z.; Haussler, C.A.; Haussler, M.R.; Jurutka, P.W. Curcumin: A novel nutritionally derived ligand of the vitamin D receptor with implications for colon cancer chemoprevention. J. Nutr. Biochem. 2010, 21, 1153-1161. [CrossRef]

91. Kunnumakkara, A.B.; Diagaradjane, P.; Anand, P.; Harikumar, K.B.; Deorukhkar, A.; Gelovani, J.; Guha, S.; Krishnan, S.; Aggarwal, B.B. Curcumin sensitizes human colorectal cancer to capecitabine by modulation of cyclin D1, COX-2, MMP-9, VEGF and CXCR4 expression in an orthotopic mouse model. Int. J. Cancer 2009, 125, 2187-2197. [CrossRef]

92. Pricci, M.; Girardi, B.; Giorgio, F.; Losurdo, G.; Ierardi, E.; Di Leo, A. Curcumin and Colorectal Cancer: From Basic to Clinical Evidences. Int. J. Mol. Sci. 2020, 21, 2364. [CrossRef] [PubMed]

93. Shoba, G.; Joy, D.; Joseph, T.; Majeed, M.; Rajendran, R.; Srinivas, P.S. Influence of piperine on the pharmacokinetics of curcumin in animals and human volunteers. Planta. Med. 1998, 64, 353-356. [CrossRef] [PubMed]

94. Di Silvestro, R.A.; Joseph, E.; Zhao, S.; Bomser, J. Diverse effects of a low dose supplement of lipidated curcumin in healthy middle aged people. Nutr. J. 2012, 11, 79. [CrossRef]

95. Wang, X.; Wang, Q.; Ives, K.L.; Evers, B.M. Curcumin inhibits neurotensin-mediated interleukin-8 production and migration of HCT116 human colon cancer cells. Clin. Cancer Res. 2006, 12, 5346-5355. [CrossRef] [PubMed]

96. Shakibaei, M.; Mobasheri, A.; Lueders, C.; Busch, F.; Shayan, P.; Goel, A. Curcumin enhances the effect of chemotherapy against colorectal cancer cells by inhibition of NF-kB and Src protein kinase signaling pathways. PLoS ONE 2013, 8, e57218. [CrossRef] [PubMed]

97. Bolat, Z.B.; Islek, Z.; Demir, B.N.; Yilmaz, E.N.; Sahin, F.; Ucisik, M.H. Curcumin- and Piperine-Loaded Emulsomes as Combinational Treatment Approach Enhance the Anticancer Activity of Curcumin on HCT116 Colorectal Cancer Model. Front. Bioeng Biotechnol. 2020, 8, 50. [CrossRef] [PubMed]

98. Zhang, C.; He, L.J.; Ye, H.Z.; Liu, D.F.; Zhu, Y.B.; Miao, D.D.; Zhang, S.P.; Chen, Y.Y.; Jia, Y.W.; Shen, J.; et al. Nrf2 is a key factor in the reversal effect of curcumin on multidrug resistance in the HCT-8/5-Fu human colorectal cancer cell line. Mol. Med. Rep. 2018, 18, 5409-5416. [CrossRef] [PubMed]

99. Villegas, I.; Sánchez-Fidalgo, S.; de la Lastra, C.A. Chemopreventive effect of dietary curcumin on inflammation-induced colorectal carcinogenesis in mice. Mol. Nutr. Food. Res. 2011, 55, 259-267. [CrossRef]

100. Kunnumakkara, A.B.; Diagaradjane, P.; Guha, S.; Deorukhkar, A.; Shentu, S.; Aggarwal, B.B.; Krishnan, S. Curcumin sensitizes human colorectal cancer xenografts in nude mice to gamma-radiation by targeting nuclear factor-kappaB-regulated gene products Clin. Cancer Res. 2008, 14, 2128-2136. [CrossRef] [PubMed]

101. Xiang, L.P.; Wang, A.; Ye, J.H.; Zheng, X.Q.; Polito, C.A.; Lu, J.L.; Li, Q.S.; Liang, Y.R. Suppressive Effects of Tea Catechins on Breast Cancer. Nutrients 2016, 8, 458. [CrossRef]

102. Cromie, M.M.; Gao, W. Epigallocatechin-3-gallate enhances the therapeutic effects of leptomycin B on human lung cancer a549 cells. Oxid. Med. Cell. Longev. 2015, 2015, 217304. [CrossRef]

103. Kumazoe, M.; Takai, M.; Hiroi, S.; Takeuchi, C.; Yamanouchi, M.; Nojiri, T.; Onda, H.; Bae, J.; Huang, Y.; Takamatsu, K.; et al. PDE3 inhibitor and EGCG combination treatment suppress cancer stem cell properties in pancreatic ductal adenocarcinoma. Sci. Rep. 2017, 7, 1917. [CrossRef]

104. Bravi, F.; La Vecchia, C.; Turati, F. Green tea and liver cancer. Hepatobiliary Surg. Nutr. 2017, 6, 127-129. [CrossRef]

105. Shirakami, Y.; Shimizu, M.; Tsurumi, H.; Hara, Y.; Tanaka, T.; Moriwaki, H. EGCG and Polyphenon E attenuate inflammationrelated mouse colon carcinogenesis induced by AOM plus DDS. Mol. Med. Rep. 2008, 1, 355-361. [CrossRef] [PubMed]

106. Shirakami, G.; Magaribuchi, T.; Shingu, K.; Suga, S.; Tamai, S.; Nakao, K.; Mori, K. Positive end-expiratory pressure ventilation decreases plasma atrial and brain natriuretic peptide levels in humans. Anesth. Analg. 1993, 77, 1116-1121. [CrossRef] [PubMed]

107. Wubetu, G.Y.; Shimada, M.; Morine, Y.; Ikemoto, T.; Ishikawa, D.; Iwahashi, S.; Yamada, S.; Saito, Y.; Arakawa, Y.; Imura, S. Epigallocatechin gallate hinders human hepatoma and colon cancer sphere formation. J. Gastroenterol. Hepatol. 2016, 31, 256-264. [CrossRef] [PubMed]

108. Alam, M.N.; Almoyad, M.; Huq, F. Polyphenols in Colorectal Cancer: Current State of Knowledge including Clinical Trials and Molecular Mechanism of Action. Biomed. Res. Int. 2018, 2018, 4154185. [CrossRef] 
109. Ogawa, K.; Hara, T.; Shimizu, M.; Nagano, J.; Ohno, T.; Hoshi, M.; Ito, H.; Tsurumi, H.; Saito, K.; Seishima, M.; et al. (-)Epigallocatechin gallate inhibits the expression of indoleamine 2,3-dioxygenase in human colorectal cancer cells. Oncol. Lett. 2012, 4, 546-550. [CrossRef]

110. Chen, Y.; Wang, X.Q.; Zhang, Q.; Zhu, J.Y.; Li, Y.; Xie, C.F.; Li, X.T.; Wu, J.S.; Geng, S.S.; Zhong, C.Y.; et al. (-)-Epigallocatechin3-Gallate Inhibits Colorectal Cancer Stem Cells by Suppressing Wnt/ $\beta$-Catenin Pathway. Nutrients 2017, 9, 572. [CrossRef] [PubMed]

111. Zhu, W.; Li, M.C.; Wang, F.R.; Mackenzie, G.G.; Oteiza, P.I. The inhibitory effect of ECG and EGCG dimeric procyanidins on colorectal cancer cells growth is associated with their actions at lipid rafts and the inhibition of the epidermal growth factor receptor signaling. Biochem. Pharmacol. 2020, 175, 113923. [CrossRef]

112. Jin, H.; Gong, W.; Zhang, C.; Wang, S. Epigallocatechin gallate inhibits the proliferation of colorectal cancer cells by regulating Notch signaling. Onco Targets Ther. 2013, 6, 145-153. [CrossRef]

113. Md Nesran, Z.N.; Shafie, N.H.; Ishak, A.H.; Mohd Esa, N.; Ismail, A.; Md Tohid, S.F. Induction of Endoplasmic Reticulum Stress Pathway by Green Tea Epigallocatechin-3-Gallate (EGCG) in Colorectal Cancer Cells: Activation of PERK/p-eIF2a/ATF4 and IRE1a. Biomed. Res. Int. 2019, 2019, 3480569. [CrossRef]

114. Maruyama, T.; Murata, S.; Nakayama, K.; Sano, N.; Ogawa, K.; Nowatari, T.; Tamura, T.; Nozaki, R.; Fukunaga, K.; Ohkohchi, N. (-)-Epigallocatechin-3-gallate suppresses liver metastasis of human colorectal cancer. Oncol. Rep. 2014, 31, 625-633. [CrossRef]

115. Hu, F.; Wei, F.; Wang, Y.; Wu, B.; Fang, Y.; Xiong, B. EGCG synergizes the therapeutic effect of cisplatin and oxaliplatin through autophagic pathway in human colorectal cancer cells. J. Pharmacol. Sci. 2015, 128, 27-34. [CrossRef]

116. Enkhbat, T.; Nishi, M.; Yoshikawa, K.; Jun, H.; Tokunaga, T.; Takasu, C.; Kashihara, H.; Ishikawa, D.; Tominaga, M.; Shimada, M. Epigallocatechin-3-gallate Enhances Radiation Sensitivity in Colorectal Cancer Cells Through Nrf2 Activation and Autophagy. Anticancer Res. 2018, 38, 6247-6252. [CrossRef]

117. Kim, W.K.; Bang, M.H.; Kim, E.S.; Kang, N.E.; Jung, K.C.; Cho, H.J.; Park, J.H. Quercetin decreases the expression of ErbB2 and ErbB3 proteins in HT-29 human colon cancer cells. J. Nutr. Biochem. 2005, 16, 155-162. [CrossRef] [PubMed]

118. Del Follo-Martinez, A.; Banerjee, N.; Li, X.; Safe, S.; Mertens-Talcott, S. Resveratrol and quercetin in combination have anticancer activity in colon cancer cells and repress oncogenic microRNA-27a. Nutr. Cancer 2013, 65, 494-504. [CrossRef] [PubMed]

119. Yang, L.; Liu, Y.; Wang, M.; Qian, Y.; Dong, X.; Gu, H.; Wang, H.; Guo, S.; Hisamitsu, T. Quercetin-induced apoptosis of HT-29 colon cancer cells via inhibition of the Akt-CSN6-Myc signaling axis. Mol. Med. Rep. 2016, 14, 4559-4566. [CrossRef] [PubMed]

120. Jin, W.; Han, H.; Ma, L.; Zhou, H.; Zhao, C. The chemosensitization effect of quercetin on cisplatin induces the apoptosis of human colon cancer HT-29 cell line. Int. J. Clin. Med. 2016, 9, 2285-2292.

121. Psahoulia, F.H.; Drosopoulos, K.G.; Doubravska, L.; Andera, L.; Pintzas, A. Quercetin enhances TRAIL-mediated apoptosis in colon cancer cells by inducing the accumulation of death receptors in lipid rafts. Mol. Cancer Ther. 2007, 6, 2591-2599. [CrossRef]

122. Kim, H.J.; Kim, S.K.; Kim, B.S.; Lee, S.H.; Park, Y.S.; Park, B.K.; Kim, S.J.; Kim, J.; Choi, C.; Kim, J.S.; et al. Apoptotic effect of quercetin on HT-29 colon cancer cells via the AMPK signaling pathway. J. Agric. Food Chem. 2010, 58, 8643-8650. [CrossRef]

123. Atashpour, S.; Fouladdel, S.; Movahhed, T.K.; Barzegar, E.; Ghahremani, M.H.; Ostad, S.N.; Azizi, E. Quercetin induces cell cycle arrest and apoptosis in CD133(+) cancer stem cells of human colorectal HT29 cancer cell line and enhances anticancer effects of doxorubicin. Iran J. Basic Med. Sci. 2015, 18, 635-643.

124. van Erk, M.J.; Roepman, P.; van der Lende, T.R.; Stierum, R.H.; Aarts, J.M.; van Bladeren, P.J.; van Ommen, B. Integrated assessment by multiple gene expression analysis of quercetin bioactivity on anticancer-related mechanisms in colon cancer cells in vitro. Eur. J. Nutr. 2005, 44, 143-156. [CrossRef]

125. Han, M.; Song, Y.; Zhang, X. Quercetin Suppresses the Migration and Invasion in Human Colon Cancer Caco-2 Cells Through Regulating Toll-like Receptor 4/Nuclear Factor-kappa B Pathway. Pharm. Mag. 2016, 12, S237-S244.

126. Zhang, X.A.; Zhang, S.; Yin, Q.; Zhang, J. Quercetin induces human colon cancer cells apoptosis by inhibiting the nuclear factor-kappa B Pathway. Pharm. Mag. 2015, 11, 404-409. [CrossRef] [PubMed]

127. Shan, B.E.; Wang, M.X.; Li, R.Q. Quercetin inhibit human SW480 colon cancer growth in association with inhibition of cyclin D1 and survivin expression through Wnt/beta-catenin signaling pathway. Cancer Investig. 2009, 27, 604-612. [CrossRef] [PubMed]

128. Richter, M.; Ebermann, R.; Marian, B. Quercetin-induced apoptosis in colorectal tumor cells: Possible role of EGF receptor signaling. Nutr. Cancer 1999, 34, 88-99. [CrossRef]

129. Özsoy, S.; Becer, E.; Kabaday, H.; Vatansever, H.S.; Yücecan, S. Quercetin-Mediated Apoptosis and Cellular Senescence in Human Colon Cancer. Anticancer Agents Med. Chem. 2020, 20, 1387-1396. [CrossRef] [PubMed]

130. Kee, J.Y.; Han, Y.H.; Kim, D.S.; Mun, J.G.; Park, J.; Jeong, M.Y.; Um, J.Y.; Hong, S.H. Inhibitory effect of quercetin on colorectal lung metastasis through inducing apoptosis, and suppression of metastatic ability. Phytomedicine 2016, 23, 1680-1690. [CrossRef]

131. Mutoh, M.; Takahashi, M.; Fukuda, K.; Komatsu, H.; Enya, T.; Matsushima-Hibiya, Y.; Mutoh, H.; Sugimura, T.; Wakabayashi, K. Suppression by flavonoids of cyclooxygenase-2 promoter-dependent transcriptional activity in colon cancer cells: Structureactivity relationship. Jpn. J. Cancer Res. 2000, 91, 686-691. [CrossRef] [PubMed]

132. Xavier, C.P.; Lima, C.F.; Rohde, M.; Pereira-Wilson, C. Quercetin enhances 5-fluorouracil-induced apoptosis in MSI colorectal cancer cells through p53 modulation. Cancer Chemother. Pharmacol. 2011, 68, 1449-1457. [CrossRef]

133. Pampaloni, B.; Palmini, G.; Mavilia, C.; Zonefrati, R.; Tanini, A.; Brandi, M.L. In vitro effects of polyphenols on colorectal cancer cells. World J. Gastrointest. Oncol. 2014, 6, 289-300. [CrossRef] [PubMed] 
134. Li, Y.; Wang, Z.; Jin, J.; Zhu, S.X.; He, G.Q.; Li, S.H.; Wang, J.; Cai, Y. Quercetin pretreatment enhances the radiosensitivity of colon cancer cells by targeting Notch-1 pathway. Biochem. Biophys. Res. Commun. 2020, 523, 947-953. [CrossRef]

135. Wang, Y.; Jin, H.Y.; Fang, M.Z.; Wang, X.F.; Chen, H.; Huang, S.L.; Kong, D.S.; Li, M.; Zhang, X.; Sun, Y.; et al. Epigallocatechin gallate inhibits dimethylhydrazine-induced colorectal cancer in rats. World J. Gastroenterol. 2020, 26, 2064-2081. [CrossRef] [PubMed]

136. Darband, S.G.; Sadighparvar, S.; Yousefi, B.; Kaviani, M.; Ghaderi-Pakdel, F.; Mihanfar, A.; Rahimi, Y.; Mobaraki, K.; Majidinia, M. Quercetin attenuated oxidative DNA damage through NRF2 signaling pathway in rats with DMH induced colon carcinogenesis. Life Sci. 2020, 253, 117584. [CrossRef] [PubMed]

137. Qi, J.; Yu, J.; Li, Y.; Luo, J.; Zhang, C.; Ou, S.; Zhang, G.; Yang, X.; Peng, X. Alternating consumption of $\beta$-glucan and quercetin reduces mortality in mice with colorectal cancer. Food Sci. Nutr. 2019, 7, 3273-3285. [CrossRef]

138. Cruz-Correa, M.; Shoskes, D.A.; Sanchez, P.; Zhao, R.; Hylind, L.M.; Wexner, S.D.; Giardiello, F.M. Combination treatment with curcumin and quercetin of adenomas in familial adenomatous polyposis. Clin. Gastroenterol. Hepatol. 2006, 4, 1035-1038. [CrossRef]

139. Guon, T.E.; Chung, H.S. Hyperoside and rutin of Nelumbo nucifera induce mitochondrial apoptosis through a caspase-dependent mechanism in HT-29 human colon cancer cells. Oncol. Lett. 2016, 11, 2463-2470. [CrossRef] [PubMed]

140. Nafees, S.; Mehdi, S.H.; Zafaryab, M.; Zeya, B.; Sarwar, T.; Rizvi, M.A. Synergistic Interaction of Rutin and Silibinin on Human Colon Cancer Cell Line. Arch. Med. Res. 2018, 49, 226-234. [CrossRef] [PubMed]

141. Ben Sghaier, M.; Pagano, A.; Mousslim, M.; Ammari, Y.; Kovacic, H.; Luis, J. Rutin inhibits proliferation, attenuates superoxide production and decreases adhesion and migration of human cancerous cells. Biomed. Pharmacother. 2016, 84, 1972-1978. [CrossRef]

142. Kuntz, S.; Wenzel, U.; Daniel, H. Comparative analysis of the effects of flavonoids on proliferation, cytotoxicity, and apoptosis in human colon cancer cell lines. Eur. J. Nutr. 1999, 38, 133-142. [CrossRef] [PubMed]

143. Alonso-Castro, A.J.; Domínguez, F.; García-Carrancá, A. Rutin exerts antitumor effects on nude mice bearing SW480 tumor. Arch. Med. Res. 2013, 44, 346-351. [CrossRef] [PubMed]

144. Gautam, R.; Singh, M.; Gautam, S.; Rawat, J.K.; Saraf, S.A.; Kaithwas, G. Rutin attenuates intestinal toxicity induced by Methotrexate linked with anti-oxidative and anti-inflammatory effects. BMC Complement Altern. Med. 2016, 16, 99. [CrossRef]

145. Fideles, L.S.; de Miranda, J.A.L.; Martins, C.D.S.; Barbosa, M.L.L.; Pimenta, H.B.; Pimentel, P.V.S.; Teixeira, C.S.; Scafuri, M.A.S.; Façanha, S.O.; Barreto, J.E.F.; et al. Role of Rutin in 5-Fluorouracil-Induced Intestinal Mucositis: Prevention of Histological Damage and Reduction of Inflammation and Oxidative Stress. Molecules 2020, 25, 2786. [CrossRef]

146. Kwon, K.H.; Murakami, A.; Tanaka, T.; Ohigashi, H. Dietary rutin, but not its aglycone quercetin, ameliorates dextran sulfate sodium-induced experimental colitis in mice: Attenuation of pro-inflammatory gene expression. Biochem. Pharmacol. 2005, 69, 395-406. [CrossRef]

147. Jang, M.; Cai, L.; Udeani, G.O.; Slowing, K.V.; Thomas, C.F.; Beecher, C.W.; Fong, H.H.; Farnsworth, N.R.; Kinghorn, A.D.; Mehta, R.G.; et al. Cancer chemopreventive activity of resveratrol, a natural product derived from grapes. Science 1997, 275, 218-220. [CrossRef]

148. Vervandier-Fasseur, D.; Latruffe, N. Cancer prevention potential of resveratrol. Molecules 2019, 24, 4506. [CrossRef]

149. Levi, F.; Pasche, C.; Lucchini, F.; Ghidoni, R.; Ferraroni, M.; La Vecchia, C. Resveratrol and breast cancer risk. Eur. J. Cancer Prev. 2005, 14, 139-142. [CrossRef]

150. Patel, K.R.; Brown, V.A.; Jones, D.J.; Britton, R.G.; Hemingway, D.; Miller, A.S.; West, K.P.; Booth, T.D.; Perloff, M.; Crowell, J.A.; et al. Clinical pharmacology of resveratrol and its metabolites in colorectal cancer patients. Cancer Res. 2010, 70, 7392-7399. [CrossRef] [PubMed]

151. Semba, R.D.; Ferrucci, L.; Bartali, B.; Urpí-Sarda, M.; Zamora-Ros, R.; Sun, K.; Cherubini, A.; Bandinelli, S.; Andres-Lacueva, C. Resveratrol levels and all-cause mortality in older community-dwelling adults. JAMA Intern. Med. 2014, 174, 1077-1084. [CrossRef] [PubMed]

152. Provinciali, M.; Re, F.; Donnini, A.; Orlando, F.; Bartozzi, B.; Di Stasio, G.; Smorlesi, A. Effect of resveratrol on the development of spontaneous mammary tumors in HER-2/neu transgenic mice. Int. J. Cancer 2005, 115, 36-45. [CrossRef] [PubMed]

153. Busquets, S.; Ametller, E.; Fuster, G.; Olivan, M.; Raab, V.; Argilés, J.M.; López-Soriano, F.J. Resveratrol, a natural diphenol, reduces metastatic growth in an experimental cancer model. Cancer Lett. 2007, 245, 144-148. [CrossRef] [PubMed]

154. Aires, V.; Limagne, E.; Cotte, A.; Latruffe, N.; Ghiringhelli, F.; Delmas, D. Resveratrol metabolites inhibit human metastatic colon cancer cells progression and synergizes with chemotherapeutic drugs to induce cell death. Mol. Nutr. Food Res. 2013, 57, 1170-1181. [CrossRef] [PubMed]

155. Abraham, S.K.; Khandelwal, N.; Hintzsche, H.; Stopper, H. Antigenotoxic effects of resveratrol: Assessment of in vitro and in vivo response. Mutagenesis 2016, 31, 27-33. [PubMed]

156. Delmas, D.; Rébé, C.; Lacour, S.; Filomenko, R.; Athias, A.; Gambert, P.; Cherkaoui-Malki, M.; Jannin, B.; Dubrez-Daloz, L.; Latruffe, N.; et al. Resveratrol-induced apoptosis is associated with Fas redistribution in the rafts and the formation of a death-inducing signaling complex in colon cancer cells. J. Biol. Chem. 2003, 278, 41482-41490. [CrossRef]

157. Aires, V.; Colin, D.J.; Agnès, A.; Di Pietro, A.; Heydel, J.M.; Artur, Y.; Latruffe, N.; Delmas, D. P-glycoprotein 1 affects chemoactivities of resveratrol against human colorectal cancer cells. Nutrients 2019, 11, 2098. [CrossRef] [PubMed] 
158. Colin, D.; Limagne, E.; Jeanningros, S.; Jacquel, A.; Lizard, G.; Athias, A.; Gambert, P.; Hichami, A.; Latruffe, N.; Solary, E.; et al. Endocytosis of resveratrol via lipid rafts and activation of downstream signaling pathways in cancer cells. Cancer Prev. Res. 2011, 4, 1095-1106. [CrossRef] [PubMed]

159. Tili, E.; Michaille, J.-J.; Alder, H.; Volinia, S.; Delmas, D.; Latruffe, N.; Croce, C.M. Resveratrol modulates the levels of microRNAs targeting genes encoding tumor-suppressors and effectors of TGF $\beta$ signaling pathway in SW480 cells. Biochem. Pharmacol. 2010, 80, 2057-2065. [CrossRef]

160. Ho, Y.; Yang, Y.C.S.; Chin, Y.T.; Chou, S.Y.; Chen, Y.R.; Shih, Y.J.; Whang-Peng, J.; Changou, C.A.; Liu, H.L.; Lin, S.J.; et al. Resveratrol inhibits human leiomyoma cell proliferation via crosstalk between integrin $\alpha \mathrm{v} \beta 3$ and IGF-1R. Food Chem. Toxicol. 2018, 120, 346-355. [CrossRef]

161. Frazzi, R.; Valli, R.; Tamagnini, I.; Casali, B.; Latruffe, N.; Merli, F. Resveratrol-mediated apoptosis of hodgkin lymphoma cells involves SIRT1 inhibition and FOXO3a hyperacetylation. Int. J. Cancer 2013, 132, 1013-1021. [CrossRef]

162. Poschner, S.; Maier-Salamon, A.; Thalhammer, T.; Jäger, W. Resveratrol and other dietary polyphenols are inhibitors of estrogen metabolism in human breast cancer cells. J. Steroid Biochem. Mol. Biol. 2019, 190, 11-18. [CrossRef] [PubMed]

163. Baarine, M.; Thandapilly, S.J.; Louis, X.L.; Mazué, F.; Yu, L.; Delmas, D.; Netticadan, T.; Lizard, G.; Latruffe, N. Pro-apoptotic versus anti-apoptotic properties of dietary resveratrol on tumoral and normal cardiac cells. Genes Nutr. 2011, 6, 161-169. [CrossRef]

164. Marel, A.K.; Lizard, G.; Izard, J.-C.; Latruffe, N.; Delmas, D. Inhibitory effects of trans-resveratrol analogs molecules on the proliferation and the cell cycle progression of human colon tumoral cells. Mol. Nutr. Food Res. 2008, 52, 538-548. [CrossRef]

165. Cilibrasi, C.; Riva, G.; Romano, G.; Cadamuro, M.; Bazzoni, R.; Butta, V.; Paoletta, L.; Dalprà, L.; Strazzabosco, M.; Lavitrano, M.; et al. Resveratrol Impairs Glioma Stem Cells Proliferation and Motility by Modulating the Wnt Signaling Pathway. PLoS ONE 2017, 12, e0169854. [CrossRef] [PubMed]

166. Yousef, M.; Vlachogiannis, I.A.; Tsiani, E. Effects of Resveratrol against Lung Cancer: In vitro and In vivo Studies. Nutrients 2017, 9, 1231. [CrossRef] [PubMed]

167. Ferrer, P.; Asensi, M.; Segarra, R.; Ortega, A.; Benlloch, M.; Obrador, E.; Varea, M.T.; Asensio, G.; Jordá, L.; Estrela, J.M. Association between pterostilbene and quercetin inhibits metastatic activity of B16 melanoma. Neoplasia 2005, 7, 37-47. [CrossRef] [PubMed]

168. Singh, S.K.; Banerjee, S.; Acosta, E.P.; Lillard, J.W.; Singh, R. Resveratrol induces cell cycle arrest and apoptosis with docetaxel in prostate cancer cells via a p53/p21WAF1/CIP1 and p27KIP1 pathway. Oncotarget 2017, 8, 17216-17228. [CrossRef] [PubMed]

169. Mertens-Talcott, S.U.; Percival, S.S. Ellagic acid and quercetin interact synergistically with resveratrol in the induction of apoptosis and cause transient cell cycle arrest in human leukemia cells. Cancer Lett. 2005, 218, 141-151. [CrossRef]

170. Mazué, F.; Delmas, D.; Murillo, G.; Saleiro, D.; Limagne, E.; Latruffe, N. Differential protective effects of red wine polyphenol extracts (RWEs) on colon carcinogenesis. Food Funct. 2014, 5, 663-670. [CrossRef]

171. Dabrowski, W.; Siwicka-Gieroba, D.; Kotfis, K.; Zaid, S.; Terpilowska, S.; Robba, C.; Siwicki, A.K. The brain-gut axis-where are we now and how can we modulate these connections? Curr. Neuropharmacol. 2020. [CrossRef]

172. Westfall, S.; Pasinetti, G.M. The Gut Microbiota Links Dietary Polyphenols with Management of Psychiatric Mood Disorders. Front Neurosci. 2019, 13, 1196. [CrossRef]

173. Shabbir, U.; Rubab, M.; Daliri, E.B.; Chelliah, R.; Javed, A.; Oh, D.H. Curcumin, Quercetin, Catechins and Metabolic Diseases: The Role of Gut Microbiota. Nutrients 2021, 13, 206. [CrossRef] [PubMed]

174. Sun, Q.; Cheng, L.; Zhang, X.; Wu, Z.; Weng, P. The interaction between tea polyphenols and host intestinal microorganisms: An effective way to prevent psychiatric disorders. Food Funct. 2021, 12, 952-962. [CrossRef]

175. Matarazzo, I.; Toniato, E.; Robuffo, I. Psychobiome Feeding Mind: Polyphenolics in Depression and Anxiety. Curr. Top. Med. Chem. 2018, 18, 2108-2115. [CrossRef]

176. Chung, J.Y.; Jeong, J.H.; Song, J. Resveratrol Modulates the Gut-Brain Axis: Focus on Glucagon-Like Peptide-1, 5-HT, and Gut Microbiota. Front. Aging Neurosci. 2020, 12, 588044. [CrossRef] [PubMed]

177. Bonferoni, M.C.; Rossi, S.; Sandri, G.; Ferrari, F. Nanoparticle formulations to enhance tumor targeting of poorly soluble polyphenols with potential anticancer properties. Semin. Cancer Biol. 2017, 46, 205-214. [CrossRef] [PubMed]

178. Summerlin, N.; Soo, E.; Thakur, S.; Qu, Z.; Jambhrunkar, S.; Popat, A. Resveratrol nanoformulations: Challenges and opportunities. Int. J. Pharm. 2015, 479, 282-290. [CrossRef] [PubMed]

179. Manconi, M.; Manca, M.L.; Escribano-Ferrer, E.; Coma-Cros, E.M.; Biosca, A.; Lantero, E.; Fernandez-Busquets, X.; Fadda, A.M.; Caddeo, C. Nanoformulation of curcumin-loaded eudragit-nutriosomes to counteract malária infection by a dual strategy: Improving anti-oxidant intestinal activity and systemic efficacy. Int. J. Pharm. 2019, 556, 82-88. [CrossRef] [PubMed]

180. Nam, J.S.; Sharma, A.R.; Nguyen, L.T.; Chakraborty, C.; Sharma, G.; Lee, S.S. Application of bioactive quercetin in oncotherapy : From nutrition to nanomedicine. Molecules 2016, 21, 108. [CrossRef]

181. Yi, Z.; Chen, G.; Chen, X.; Sun, Z.; Ma, X.; Su, W.; Deng, Z.; Ma, L.; Ran, Y.; Tong, Q.; et al. Molecular assembly of versatile nanoparticles with epigallocatechin gallate. ACS Sustain. Chem. Eng. 2020, 8, 9833-9845. [CrossRef]

182. Dutta, D.; Chakraborty, A.; Mukherjee, B.; Gupta, S. Aptamer-conjugated apigenin nanoparticles to target colorectal carcinoma: A promising safe alternative of colorectal cancer chemotherapy. ACS Appl. Bio Mater. 2018, 1, 1538-1556. [CrossRef]

183. Gao, X.; Wang, B.L.; Wei, X.W.; Men, K.; Zheng, F.; Zhou, Y.; Zheng, Y.; Gou, M.L.; Huang, M.; Guo, G.; et al. Anticancer effect and mechanism of polymer micelle-encapsulated quercetin on ovarian cancer. Nanoscale 2012, 4, 7021-7030. [CrossRef] 
184. Xu, G.; Shi, H.; Ren, L.; Gou, H.; Gong, D.; Gao, X.; Huang, N. Enhancing the anti-colon cancer activity of quercetin by self-assembled micelles. Int. J. Nanomed. 2015, 10, 2051-2063.

185. Coimbra, M.; Isacchi, B.; van Bloois, L.; Torano, J.S.; Ket, A.; Wu, X.; Broere, F.; Metselaar, J.M.; Rijcken, C.J.F.; Storm, G.; et al. Improving solubility and chemical stability of natural compounds for medicinal use by incorporation into liposomes. Int. J. Pharm. 2011, 416, 433-442. [CrossRef]

186. Feng, M.; Zhong, L.X.; Zhan, Z.Y.; Huang, Z.H.; Xiong, J.P. Enhanced antitumor efficacy of resveratrol-loaded nanocapsules in colon cancer cells: Physicochemical and biological characterization. Eur. Rev. Med. Pharmacol. Sci. 2017, 21, 375-382.

187. Soo, E.; Thakur, S.; Qu, Z.; Jambhrunkar, S.; Parekh, H.S.; Popat, A. Enhancing delivery and cytotoxicity of resveratrol through a dual nanoencapsulation approach. J. Colloid Interface Sci. 2016, 462, 368-374. [CrossRef]

188. Sudha, T.; El-Far, A.H.; Mousa, D.S.; Mousa, S.A. Resveratrol and its nanoformulation attenuate growth and the angiogenesis of xenograft and orthotopic colon cancer models. Molecules 2020, 25, 1412. [CrossRef]

189. Wong, K.E.; Ngai, S.C.; Chan, K.G.; Lee, L.H.; Goh, B.H.; Chuah, L.H. Curcumin Nanoformulations for Colorectal Cancer: A Review. Front. Pharmacol. 2019, 10, 152. [CrossRef]

190. Chun, J.; Li, R.J.; Cheng, M.S.; Kim, Y.S. Alantolactone selectively suppresses STAT3 activation and exhibits potent anticancer activity in MDA-MB-231 cells. Cancer Lett. 2015, 357, 393-403. [CrossRef]

191. Zhang, J.; Shen, L.; Li, X.; Song, W.; Liu, Y.; Huang, L. Nanoformulated codelivery of quercetin and alantolactone promotes an antitumor response through synergistic immunogenic cell death for microsatellite-stable colorectal cancer. ACS Nano 2019, 13, 12511-12524. [CrossRef]

192. Kasala, E.R.; Bodduluru, L.N.; Madana, R.M.V.; Athira, K.; Gogoi, R.; Barua, C.C. Chemopreventive and therapeutic potential of chrysin in cancer: Mechanistic perspectives. Toxicol. Lett. 2015, 233, 214-225. [CrossRef]

193. Lotfi-Attari, J.; Pilehvar-Soltanahmadi, Y.; Dadashpour, M.; Alipour, S.; Farajzadeh, R.; Javidfar, S.; Zarghami, N. Co-delivery of curcumin and chrysin by polymeric nanoparticles inhibit synergistically growth and hTERT gene expression in human colorectal cancer cells. Nutr. Cancer 2017, 69, 1290-1299. [CrossRef]

194. Yaffe, P.B.; Power Coombs, M.R.; Doucette, C.D.; Walsh, M.; Hoskin, D.W. Piperine, an alkaloid from black pepper, inhibits growth of human colon cancer cells via G1 arrest and apoptosis triggered by endoplasmic reticulum stress. Mol. Carcinog. 2015, 54, 1070-1085. [CrossRef]

195. Patial, V.; Mahesh, S.; Sharma, S.; Pratap, K.; Singh, D.; Padwad, Y.S. Synergistic effect of curcumin and piperine in suppression of DENA-induced hepatocellular carcinoma in rats. Environ. Toxicol. Pharmacol. 2015, 40, 445-452. [CrossRef]

196. Milincic, D.D.; Popovic, D.A.; Levic, S.M.; Kostic, A.Z.; Tesic, Z.L.; Nedovic, V.A.; Pesic, M.B. Application of polyphenol-loaded nanoparticles in food chemistry. Nanomater 2019, 9, 1629. [CrossRef]

197. Decker, E.A. Phenolics: Prooxidants or antioxidants? Nutr. Rev. 1997, 55, 396-398. [CrossRef]

198. Borowska, S.; Brzoska, M.M.; Tomczyk, M. Complexation of bioelements and toxic metals by polyphenolic compoundsImplications for health. Curr. Drug Targets 2018, 19, 1612-1638. [CrossRef] 